NBER WORKING PAPER SERIES

\title{
INTENSIVE MEDICAL CARE AND CARDIOVASCULAR DISEASE DISABILITY REDUCTIONS
}

\author{
David M. Cutler \\ Mary Beth Landrum \\ Kate A. Stewart \\ Working Paper 12184 \\ http://www.nber.org/papers/w12184
NATIONAL BUREAU OF ECONOMIC RESEARCH
1050 Massachusetts Avenue
Cambridge, MA 02138
April 2006

We are grateful to the National Institutes on Aging and the Lasker Foundation for research support. The views expressed herein are those of the author(s) and do not necessarily reflect the views of the National Bureau of Economic Research.

(C2006 by David M. Cutler, Mary Beth Landrum and Kate A. Stewart. All rights reserved. Short sections of text, not to exceed two paragraphs, may be quoted without explicit permission provided that full credit, including $(\odot)$ notice, is given to the source. 
Intensive Medical Care and Cardiovascular Disease Disability Reductions

David M. Cutler, Mary Beth Landrum and Kate A. Stewart

NBER Working Paper No. 12184

April 2006

JEL No. I1, J1

\begin{abstract}
There is little empirical evidence to explain why disability declined among the elderly over the past 20 years. In this paper, we explore the role of improved medical care for cardiovascular disease on health status improvements over time. We show that the incidence of cardiovascular disease hospitalizations remained relatively constant between 1984 and 1999 at the same time that post-event survival improved and disability declined. We find that use of appropriate therapies, including pharmaceuticals such as beta-blockers, aspirin, and ace-inhibitors, and invasive procedures, explains up to $50 \%$ and $70 \%$ of the reductions in disability and death over time, respectively. Elderly patients living in regions with high use of appropriate medical therapies had better health outcomes than patients living in low-use areas. Finally, we estimate that preventing disability after an acute event can add as much as 3.7 years of quality-adjusted life expectancy, or $\$ 316,000$ of value.
\end{abstract}

David M. Cutler

Department of Economics

Harvard University

1875 Cambridge Street

Cambridge, MA 02138

and NBER

dcutler@harvard.edu

Mary Beth Landrum

Harvard Medical School

Department of Health Care Policy

180 Longwood Avenue

Boston, MA 02115-5899

landrum@hcp.med.harvard.edu

Kate A. Stewart

Harvard Medical School

Department of Health Care Policy

180 Longwood Avenue

Boston, MA 02115-5899

kstewart@hsph.harvard.edu 
Disability among the elderly has declined markedly in the United States in the past two decades. In 1984, 25 percent of the elderly population reported difficulty with activities associated with independent living. ${ }^{1}$ By 1999 , the share had fallen to 20 percent, a decline of one-fifth.

Although these basic facts are well known, the interpretation of these facts is not clear. Is the reduction in disability a result of improved medical care, individual behavioral changes, or environmental modifications that allow the elderly to better function by themselves? Will the trend continue, or is it time limited? What does the reduction in disability mean for years of healthy life and labor force participation? We explore these issues in this paper.

To make progress, we focus on disability caused by a specific set of medical conditions: cardiovascular disease. Focusing on one condition is helpful because it allows us to analyze health shocks and their sequellae in some detail. Cardiovascular disease is a natural condition to pick because it is the most common cause of death in the US (and most other developed countries), and more is spent on cardiovascular disease than any other condition. Thus, this is a case where medical care could really matter.

Our analysis has three parts. In the first part, we examine basic trends in disability associated with cardiovascular disease. We show that reduced disability for people with cardiovascular disease incidents is a major part of reductions in overall disability, accounting for between one-fifth and one-third of the total reduction in disability. The second part of the paper considers the role of advances in medical care in reducing disability from cardiovascular disease. We show that medical technology in the treatment of cardiovascular disease is a major factor in reduced disability. We estimate that use of recommended treatments for heart attacks, including

\footnotetext{
${ }^{1}$ The data are from the National Long-Term Care Survey, a survey we describe later and use in this paper.
} 
prescriptions of beta-blockers, aspirin and ace-inhibitors at discharge, as well as use of reperfusion and other surgical procedures increased the probability that elderly patients survive an acute cardiovascular event in a non-disabled state by 13 to 22 percent between 1984 and 1994. The third part of the paper considers the long-run health and financial impacts of improved care for people with cardiovascular disease.

\section{Background on Cardiovascular Disease}

Cardiovascular diseases are diseases of the heart and blood vessels which carry oxygen to the body's major organs. Ischemic heart disease is the most common manifestation of cardiovascular disease. When the arteries supplying blood to the heart become occluded, the heart does not get enough oxygen. Like any muscle, oxygen is essential for the heart's performance. Constriction of the coronary arteries will result in chest pain on exertion, or perhaps at rest. A person with such constriction might be unable to engage in activities such as walking for a prolonged period (for example, to get to a grocery store) or engaging in light or heavy housework (cleaning, cooking, etc.)

A blockage of the arteries to some or all of the heart is termed a myocardial infarction, or heart attack. The equivalent in other extremities, especially the legs, is termed peripheral vascular disease. Heart attacks can be fatal, and can lead to substantial disability if survived. A person who survives a heart attack might be unable to shop or cook, might have difficulty walking up stairs or entering a raised bathtub, and might have difficulty keeping house. Peripheral vascular disease can lead to the same types of impairments.

Medical advance has made tremendous strides in preventing and treating coronary events. Several risk factors for heart disease are well known. Traditional risk factors include smoking; 
hypertension or high blood pressure; high cholesterol; obesity; family history, age and diabetes. Since the early 1970s, standard recommendations for people at risk have been behavioral changes (stop smoking, reduce weight, cut back on fat intake, and exercise) combined with medical therapy (antihypertensive medication, and more recently cholesterol-reducing medications). (Cutler and Kadiyala 2003) show significant reductions in the incidence of heart disease over time attributable to reductions in these risk factors, especially reduced smoking and better blood pressure control.

There have also been technological changes in the treatment available for people with severe heart disease. Bed rest was once standard therapy for people with heart attacks. Today, therapy for a heart attack, and often heart disease in earlier stages of progression, generally starts with drugs such as aspirin help dissolve clots and restore blood flow to the heart. Beta-blockers are also given to reduce the workload of the heart, and thus reduce the demand for oxygen. In addition, ace-inhibitors are prescribed to help reduce the workload of the heart by lowering blood pressure Statins are prescribed to help process and break down cholesterol in the arteries (American Heart Association 2006).

Finally, there have been significant advances in acute care and invasive surgical procedures for treating coronary blockage. Thrombolytics are a class of drugs that may be used to help dissolve the clot. Percutaneous coronary intervention (PCI) is used to clear out blockages of the coronary arteries. These procedures are now frequently accompanied by use of a stent to keep the occluded artery open. A more invasive option is coronary artery bypass grafting (abbreviated CABG, and pronounced like the vegetable).

Each of these technologies has been shown to increase survival after a heart attack among patients without contraindications for treatment (Krumholz, Radford et al. 1995; Hennekens, 
Albert et al. 1996; Krumholz, Radford et al. 1996; Soumerai, McLaughlin et al. 1997; Gottlieb, McCarter et al. 1998; Krumholz, Radford et al. 1998; Freemantle, Cleland et al. 1999; Shlipak, Browner et al. 2001; Braunwald, Antman et al. 2002; Antman, Anbe et al. 2004; Vitagliano, Curtis et al. 2004; Stukel, Lucas et al. 2005). They have an ambiguous effect on disability, however, with the increase in survival among those with serious heart damage possibly offsetting the improved health among traditional survivors (Crimmins, Saito et al. 1989; Crimmins, Hayward et al. 1994; Waidmann, Bound et al. 1995).

Cerebrovascular disease, or stroke, is the second major form of cardiovascular disease. Ischemic strokes are the most common type of stroke, and are similar to heart disease: an artery in the brain becomes blocked, and a part of the brain is denied oxygen. Disability is quite common after a stroke, particularly among the elderly (Pohjasvaara, Erkinjuntti et al. 1997; Prencipe, Ferretti et al. 1997; Zhu, Fratiglioni et al. 1998). Recent studies report that $39 \%$ to 54\% of stroke survivors are disabled 3-months after the stroke (Henon, Godefroy et al. 1995; Zhu, Fratiglioni et al. 1998; Glader, Stegmayr et al. 2003). The high level of disability can persist among survivors. One study found $37 \%$ of stroke survivors were disabled one year after the event (Appelros, Nydevik et al. 2003). In addition, stroke is associated with increased odds of cognitive impairment, both with and without dementia (Pohjasvaara, Erkinjuntti et al. 1997; Prencipe, Ferretti et al. 1997; Zhu, Fratiglioni et al. 1998).

Thrombolytic medication might be given after a stroke, but the benefit is far less certain than in heart disease. Clinical trials show that thrombolytics are effective only if given in the first three hours after an acute event (Group 1995; Clark, Wissman et al. 1999; Adams, Adams et al. 2005). Revascularization procedures such as carotid endarterectomy may be performed in patients with certain types of stroke, including transient ischemic attacks, after the patients have 
recovered from the acute phase of the stroke. A small share of strokes are hemorrhagic strokes, where a blood vessel bursts and there is bleeding in the skull. Little therapy is generally available in such cases, and death is common.

Heart failure and arrhythmias are other types of cardiovascular disease that cause substantial morbidity and mortality among the elderly. Heart failure occurs when the heart's ability to pump blood is impaired. Patients may experience breathlessness and fatigue that makes it difficult to keep up usual activities, fluid retention and edema, coughing, memory loss and heart palpitations. An arrhythmia is an irregular heartbeat that can cause the heart to pump blood less effectively. Patients with heart failure and/or arrhythmias may also be at substantial risk for stroke and other complications (American Heart Association 2006). Treatment for heart failure includes ace-inhibitors or angiotensin II receptor blockers, beta-blockers, and diuretics. Appropriate patients may also undergo valve replacement surgery or other revascularization. Patients with arrhythmias often receive pacemakers and occasionally receive implantable cardioverter defibrillators along with antiarrhythmic drugs and blood thinners.

Other cardiovascular diseases, generally with smaller prevalence, include rheumatic heart disease, aneurysms, acute pulmonary heart disease, other diseases of the endocardium, capillary diseases, and problems with veins (e.g. varicose veins).

\section{The Importance of Cardiovascular Disease for Reductions in Disability}

Like every multidimensional concept, there is no perfect measure of disability. We follow the lead of most researchers in measuring disability as the presence of impairments in Activities of Daily Living (ADLs) and Instrumental Activities of Daily Living (IADLs). Our data source, the National Long-Term Care Survey of 1984-1999 - abbreviated NLTCS - includes 
information on 6 ADL measures: eating, getting in or out of bed, walking around inside, dressing, bathing, and getting to the toilet or using the toilet. Questions are also asked about 8 IADL measures: doing light housework, laundry, preparing meals, shopping for groceries, getting around outside, managing money, taking medications and making telephone calls.

The NLTCS is a nationally-representative longitudinal survey of the health and disability profile population aged 65 and over. The first NLTCS survey wave was conducted in 1982 and subsequent surveys were administered in 1984, 1989, 1994 and 1999. Each survey wave began with a screener that collected information on whether the respondent reported difficulty conducting the 6 ADLs and 8 IADLs without help (i.e. help from another person or special equipment), and whether any difficulty had lasted or was expected to last at least 3 months. The screener also collected demographic information on marital status, race and age.

Respondents who reported difficulty with any ADLs or IADLs for at least 3 months on the screener were asked to complete a detailed survey. Disability status was determined by responses to questions about use of help and inability to conduct the ADLs and IADLs on the detailed survey. Sampling and weighting issues are described fully elsewhere (Manton, Corder et al. 1993; Manton, Corder et al. 1997; Manton, Stallard et al. 1997; Singer and Manton 1998; Manton and Gu 2001).

We obtained Medicare-linked data for all NLTCS participants, including data on date of death from the denominator files. We used inpatient claims for all analyses, because Medicare claims files for part B and other non-hospital services were incomplete prior to 1991. We also obtained data on zip code of residence at the most recent interview for all NLTCS survey respondents. 
Basic data on disability among the elderly population is shown in Figure 1. For reasons that will become clear briefly, we report disability for the population that is aged 70 and older in each of three years: 1989, 1994, and 1999. The share of the elderly population that is disabled declined markedly in the decade of the 1990s. The cumulative decline was 6.3 percentage points, or 2.1 percent per year.

To examine the role of cardiovascular disease in explaining this reduction in disability, we form a population sample likely affected by the condition. We start by looking at the population aged 70 and older in the 1989, 1994, and 1999 surveys. For each of these cohorts, we group all hospitalizations over the preceding 5 years into one of 32 categories (the five year look back is the reason for the restriction to people over 70). These categories were designed to pick up relatively homogenous clinical conditions that would be predictive of disability. The set of 32 categories is shown in Table 1, along with the rate of disability for people hospitalized with each condition from the 1989 survey cohort. The relevant categories for cardiovascular disease are stroke, hypertension, ischemic heart disease, heart failure and arrhythmia, peripheral vascular disease, and other circulatory diseases. ${ }^{2}$

Figure 2 reports the share of people with a hospitalization for any of these conditions. Twenty-two percent of people were admitted to a hospital with some cardiovascular disease. Ischemic heart disease is the most common admission, accounting for 8 percent of admissions. Stroke and heart failure are also common, as are other circulatory diseases. Admissions for peripheral vascular disease and hypertension are much less common.

\footnotetext{
2 ICD-9 codes are as follows: stroke: 362.34, 430, 431, 432.9, 433-436; hypertension: 401-402, 405, 437.0, 437.9; ischemic heart disease; 4.10-4.14, 429.5-429.7, excluding 414.11 and 414.19; heart failure and arrhythmia: 425, 427.1, 427.3-427.5, 428, 429.1, 429.3; peripheral vascular disease: 440, 442, 443.0 - 443.1, 443.8 - 443.9, 444, 446, 447.0-447.5, 447.8-447.9, 451, 453.1; and circulatory diseases: 391-400, 406-409, 414.11, 414.19, 415-424, 426, 427.2, 427.6, 427.8, 427.9, 429.2, 429.4, 429.8, 429.9, 432.1 - 432.8, 437.1 - 437.8, 439, 441, 443.2, 445, 447.6, 448 - 450, 452 - 453.0, 453.2 - 459, 786.5, V717.
} 
A person who had a hospital admission for cardiovascular disease and is disabled may or may not have been disabled because of that condition. The NLTCS does not reliably determine the precise condition that leads to each disability (Landrum and Stewart 2006). We make two alternative assumptions about the probability of being disabled by cardiovascular disease. The first assumption, a less restrictive assumption, labels someone as disabled from cardiovascular disease if they were admitted to a hospital with cardiovascular disease in the previous five years. The more restrictive assumption subsets this group to those for whom the most disabling condition was cardiovascular disease ${ }^{3}-$ where the list of conditions by disability status is reported in Table 1. Thus, a person who had a stroke and hip fracture would be termed disabled because of cardiovascular disease by the first measure, but not by the second measure. Fortunately, our results are very similar regardless of the definition used

Figure 3 shows the probability of being disabled by cardiovascular disease. Using the less restrictive measure, the decline in disability is 1.4 percentage points, or 22 percent of the 6.3 percentage point total reduction in disability. Using the more restrictive measure, the decline is 0.9 percentage points, or 14 percent of the total decline. In each case, cardiovascular disease is a substantial share of the total decline.

As noted above, the conclusion that cardiovascular disease is a substantial share of disability decline contradicts an earlier literature that suggested that 'marginal survivors' contribute to an increase in disability. If more people survive strokes, the argument went, the share of the elderly with disabilities would rise. The finding of a reduction in disability suggests, in contrast, two other hypotheses: either fewer people are suffering cardiovascular disease events; or those who have always survived such events are less disabled now than they were

\footnotetext{
${ }^{3}$ Note even this more restrictive assumption may underestimate the importance of disabling diseases, such as arthritis or dementia, that are not common causes of hospitalizations.
} 
formerly, i.e. the incidence of disability among cardiovascular disease patients is falling. These possible effects are demonstrated in equation (1):

$$
\begin{aligned}
\operatorname{Pr}[\text { Disabled from CVD }]=\operatorname{Pr}[\text { Had CVD Incident }] * \operatorname{Pr}[\text { Survive } \mid \text { Had Event }] * \\
\\
\operatorname{Pr}[\text { Disabled } \mid \text { Had Event, Survival }]
\end{aligned}
$$

The first term on the right hand side is the incidence of events. The second term is the survival rate, and the third term is the health effect among survivors. The change in disability rates is arithmetically related to the change in one or more of these factors. ${ }^{4}$ The marginal survivors theory focuses on the second term: the change in the probability of survival after an acute event, i.e. as more patients survive acute events, the pool of people at risk of disability expands. The other theories focus on the first and third terms, i.e. either reduced incidence of disease or better health among survivors.

Table 2 shows cardiovascular disease event probabilities, survival rates, and conditional disability rates for each of our three time periods. To measure the cardiovascular disease event rate, we consider the population surveyed at the beginning of the 5-year interval, and look at events in those five years. For example, the cardiovascular disease event rate for the 1989 cohort is the share of the population aged 65 and older in 1984 that had a cardiovascular disease hospital admission in the subsequent five years. ${ }^{5}$

\footnotetext{
4 There are covariance terms as well, but these are generally small.

${ }^{5}$ Were the NLTCS a fixed panel survey, the sample of people at the starting year (for example 1984) would be only those for whom the disability status is known five years later plus those who died in the interim. The NLTCS did not interview the entire sample every year, however, so some people are lost to follow-up. To generate a nationally representative sample, we analyzed only those people whose health and mortality status were known at follow-up for each survey year, and re-weighted the sample weights to reflect the age-sex distribution of all respondents to the 1999 survey.
} 
The first row shows that the share of people who had a hospitalization for cardiovascular disease was relatively constant over the time period, at about 26 percent. This is somewhat surprising given the reduction in event rates noted in other surveys such as the Framingham Heart Study (Sytkowski, D'Agostino et al. 1996) and the Minnesota Heart Survey (McGovern, Pankow et al. 1996; McGovern, Jacobs et al. 2001). It may be that some of the admissions among the later cohorts in our study were done explicitly to perform surgical operations such as angioplasty or bypass surgery, and thus contribute to an increased reporting of cardiovascular disease. However, another recent U.S. study of subjects aged 35 to 74 reported little change in the incidence of first myocardial infarction between 1987 and 1994 (Rosamond, Chambless et al. 1998). Alternatively, it may be that less severe cases of these conditions are being diagnosed over time. ${ }^{6}$

In addition, the Framingham and Minnesota studies included patients younger than 65, and results from these studies may have been driven by a decline in heart disease among the younger population. A Finnish study of coronary heart disease between 1978-1980 and 20002001 reported decreased prevalence of coronary heart disease among men and women aged 45 to 64 years, no change in prevalence among men and women aged 65 to 74 and increased incidence among people aged 75 and over (Kattainen, A. et al. 2004). Our results may reflect similar trends in age-related incidence of heart disease.

The second row of the table shows a significant increase in the survival rate to the next survey for people admitted to a hospital with cardiovascular disease. The survival rate increased by 4.3 percentage points, or about 7.5 percent. By itself, this would have led to an increase in disability from cardiovascular disease. This effect is overwhelmed, however, by the substantial

\footnotetext{
${ }^{6}$ Clinical trials published in 1996 showed that a blood test for troponin, a protein released from damaged heart tissue, can be used to diagnose heart attacks. This likely led to greater diagnosis of smaller heart attacks, and may also have led to increased hospitalizations, depending on how frequently these patients were previously admitted.
} 
reduction in disability among survivors, shown in the third row of the table. The share of CVD survivors who are disabled fell from 48 percent in 1989 to 39 percent in 1999, a 19 percent reduction. It is this massive reduction in event-specific disability that needs to be explained.

\section{Medical Care and CVD-Related Disability}

Before estimating formal statistical models to address the role of medical care in reduced CVD-related disability, we consider a less structural analysis of the role of medical care. Specifically, we look at how disability changed in the period shortly after the cardiovascular disease event relative to the period several years later. If the reduction in disability followed immediately after the cardiovascular event, it strongly suggests that medical treatment of the acute event was the major factor responsible for the reduction in disability. A disability reduction further out in time might be attributable to medical intervention, but other factors, such as better coping with limitations due to improved environmental factors, could be important as well.

Figure 4 shows the change in disability rates for people whose cardiovascular disease event happened within 6 months of the survey, by type of event. The rate of disability declined from 1984-1989 cohort to the 1994-1999 cohort for people with hospitalizations for ischemic heart disease, heart failure and arrhythmia, stroke and other cardiovascular disease. For heart failure and arrhythmia patients as well as other cardiovascular diseases, there were increases in the disability rate from the 1984-1989 to 1989-1994 cohorts that need further explanation ${ }^{7}$. Overall, though, it seems that medical advances could have some role in this change decline in disability between 1984-1989 and 1994-1999.

\footnotetext{
${ }^{7}$ For example, the average severity of heart failure hospitalizations may have increased over time if physicians and patients were better able to manage heart failure in the outpatient setting.
} 


\section{Empirical Methodology}

To examine the role of medical technology changes in event-related reductions in disability more formally, we estimate regression models for the health of patients who have been admitted to a hospital with cardiovascular disease. Our sample is formed from each of the three cohorts. We select people who were admitted to a hospital with cardiovascular disease in the 1984-89 period, the 1989-94 period, and the 1994-99 period. In each case, the sample includes all people for whom we know health status at the beginning and end of the 5-year period. There are three possible health states at the end of each period, i.e. at the time of follow-up survey: dead; alive and non-disabled; and alive and disabled. We denote these possible outcomes with the subscript $k$.

Consider for the moment a single measure of medical treatments, which we wish to relate to the change in disability. For concreteness, assume that the variable is the share of people in an area who receive a surgical procedure that has been shown to be effective in improving health for people with that condition. The treatment rate for area $j$ in time period $t$ is denoted $T_{j, t}$. We model the probability that person $i$ will be in health state $k$ using a multinomial logit formulation:

$$
\begin{aligned}
& \operatorname{Pr}[\text { health state } \mathrm{k}]_{\mathrm{i}, \mathrm{j}, \mathrm{t}}= \\
& \quad \exp \left(\mathbf{X}_{\mathrm{i}, \mathrm{t}} \boldsymbol{\beta}_{\mathrm{k}}+\gamma_{\mathrm{k}} \mathrm{T}_{\mathrm{j}, \mathrm{t}}+\Delta_{\mathrm{k}} \text { cohort }_{\mathrm{t}}\right) /\left(1+\exp \left(\Sigma \mathbf{X}_{\mathrm{i}, \mathrm{t}} \boldsymbol{\beta}_{1}+\gamma_{1} \mathrm{~T}_{\mathrm{j}, \mathrm{t}}+\Delta_{\mathrm{l}} \text { cohort }_{\mathrm{t}}\right)\right.
\end{aligned}
$$

where $\mathbf{X}_{\mathrm{i}, \mathrm{t}}$ is a set of demographic variables, $\gamma_{\mathrm{k}}$ 's are the coefficient of interest. Our demographic variables include age/sex (five year age groups differentiated by gender); dummy variables for other cardiovascular disease hospitalizations, a modified Charlson index (i.e. without 
cardiovascular disease diagnoses) (Deyo, Cherkin et al. 1992) marital status at the beginning of the five year window (married; widowed; and divorced/separated); and race (white and nonwhite).

One issue that comes up in any estimation involving an equation like (2) is the issue of causality. If treatments are not randomly assigned, estimates of $\gamma$ will be biased. We address this issue in several ways. The most important is to use area-level variation in treatments, rather than individual-level variation. Whether any individual receives a treatment is dependent on the physician's perception of that patient's underlying health. If the underlying severity of disease is relatively constant across areas and over time, however, variations in treatment at the area level will be good markers for exogenous changes in the use of medical care. As is standard in the literature (O'Connor, Quinton et al. 1999; Fisher, Wennberg et al. 2003; Fisher, Wennberg et al. 2003; Stukel, Lucas et al. 2005), we group individuals into areas based on the Hospital Referral Region (HRR) they live in. HRRs are groups of zip codes where the bulk of patients go to the same set of hospitals and include at least one hospital with a tertiary cardiovascular or neurological surgical center. For example, the HRR for Chicago includes zip codes 6060160712; within this area, the vast majority of people who are hospitalized get admitted to a hospital in that region.

To facilitate interpretation of the results, we center all demographic and HRR-level covariates. This allows us to interpret the coefficients on the survey year dummy variables as the change in the log-odds of disability and death relative to being alive and non-disabled for the average person living in the average area across survey cohorts. We also begin our analyses with models that include only survey year dummy variables and demographic and health status covariates. We compare these models to models that include cardiovascular disease medical 
treatments to evaluate whether including treatment in the models changes the association between survey year and the likelihood of death and disability for the average patient.

\section{Measures of Medical Treatment}

We use several measures of medical care to predict disability. The first variable is the share of people who receive surgical interventions. To define relevant procedures, we identify treatments for each specific diagnosis that the medical literature has identified as being efficacious (generally in reducing mortality) for at least some subsets of patients with that diagnosis. These procedures are detailed in table 3. For hypertension, there are no generally accepted surgical therapies. There are one or more therapies for the other conditions, of which the most common appropriate procedures are "other operations on the heart and blood vessels" (CPT code 37), which includes PCI (angioplasty), heart replacement procedures and insertion of pace-makers, and "incision, excision and occlusion of vessels" (CPT code 38), which includes endarterectomies. CABG procedures for ischemic heart disease patients are coded under CPT code 36, "Operations on vessels of heart".

Table 4 shows the average rate of procedure use over time across hospital referral regions, for all cardiovascular disease patients and by specific conditions. In the 1984-89 cohort, the average procedure rate was only 21 percent across regions. The average procedure rate was highest for other circulatory diseases (30\%), followed by ischemic heart disease (23\%), stroke (13\%) and heart failure and arrhythmia (11.3\%). By 1994-1999, the average procedure rate for all patients across all regions increased to $34 \%$. The average procedure rate for ischemic heart disease patients jumped to $48 \%$. Average procedure rates increased to $43 \%$ for other circulatory 
diseases, $25 \%$ for stroke and $14.2 \%$ for heart failure and arrhythmia. These increases reflect the greater belief among physicians about the efficacy of therapy, and advances in the therapy itself. ${ }^{8}$

Our other measures of medical technology involve use of pharmaceuticals for patients with acute myocardial infarction. As noted in the previous section, these pharmaceuticals have been shown to improve survival, although the overall effect of pharmaceutical treatment on both improved survival and disability in the elderly has not been well-established. Randomized studies comparing various treatments for ischemic heart disease on functional status and quality of life reported improvements for most outcome measures for both medical and surgical therapies (Rogers, Coggin et al. 1990; Strauss, Fortin et al. 1995; Hlatky, Rogers et al. 1997; Pocock, Henderson et al. 2000; Borkon, Muehlebach et al. 2002; Pfisterer, Buser et al. 2003). . However, most of these studies included patients under age 65 who may be more likely to improve than elderly patients (Rogers, Coggin et al. 1990; Strauss, Fortin et al. 1995; Hlatky, Rogers et al. 1997; Pocock, Henderson et al. 2000; Borkon, Muehlebach et al. 2002). A recent trial comparing medical and surgical management of elderly patients with coronary artery disease reported improved quality of life at one year for both treatment arms (Pfisterer, Buser et al. 2003), suggesting that treatment likely reduces disability in the elderly population. However, no studies to date have estimated the effect of increased use of appropriate pharmaceutical treatments over time on disability rates in the elderly population.

Pharmaceutical use is not captured in Medicare claims, since Medicare does not pay more for use of pharmaceuticals. Thus, we do not have time series data on the use of pharmaceuticals by area. We do have a snapshot of data on pharmaceutical use, taken from a survey of medical records in the mid-1990s. The cooperative Cardiovascular Project (CCP) abstracted medical

\footnotetext{
${ }^{8}$ For example, catheters used in surgery have improved, and stents were developed for use in angioplasty in the mid 1990s.
} 
record data on 186,800 Medicare patients hospitalized for an AMI between February 1994 and July 1995 including data on appropriateness for and receipt of guideline recommended treatments (Marciniak, Ellerbeck et al. 1998).

Use among patients most suited for treatment ranged from $51 \%$ for beta-blockers in the immediate post-myocardial infarction treatment to $76 \%$ for aspirin. Average utilization rates for the mid-1990s are shown in table 4. Researchers at Dartmouth have calculated the average use rate of each of these pharmaceuticals at the HRR level, which we employ in our analysis (O'Connor, Quinton et al. 1999).

While not known at the area level, use of these pharmaceuticals did increase during our study timeframe. Reported use of aspirin for heart attack patients in 1985 and 1995 was 30\% and $75 \%$, respectively, and over the same time, use of beta blockers was $48 \%$ and $50 \%$, thrombolytics was $9 \%$ and $31 \%$, and ace-inhibitors was $0 \%$ and $21 \%$, respectively (Heidenreich and McClellan 2001). The change in ace-inhibitors use from this study was based only on changes in the Worcester, Massachusetts area and may not reflect changes in use nationally.

For patients with heart failure and stroke we employed published data on state-wide use of evaluation of ejection fraction (heart failure) and use of warfarin for patients with atrial fibrillation and prescription of antithrombotics at discharge for patients with acute stroke or transient ischemic attack (stroke) from 2000-2001 (Jencks, Huff et al. 2003).

The lack of time series data on pharmaceutical use at the area level requires us to make one change in the analysis. Equation (2) assumes that the procedure has the same effectiveness over time. Since use of pharmaceuticals increased over time, we would expect that the coefficient on pharmaceutical use would be greater for the 1994-99 cohort than for the 1984-89 
cohort; more patients, after all, would have been treated with the technology. To account for this phenomenon, we interact each treatment variable with the survey year dummy variables.

From our models, we estimate the likelihood of being disabled, dead and alive and nondisabled at follow-up if all respondents lived in HRRs that provided relevant procedures and pharmaceuticals at the $10^{\text {th }}$ and $90^{\text {th }}$ percentiles of care, holding all other covariates constant. We develop separate estimations for relevant procedures and pharmaceuticals to better understand the effect of each treatment type on changes in death and disability over time.

\section{Estimation Results}

Table 5 shows demographic characteristics of our cohort by year of baseline survey. The proportion of respondents disabled at baseline declined over time, from $32 \%$ in 1984 to $25.9 \%$ in 1994. This 6 percentage point decline in disability at baseline is consistent with other analyses using the NLTCS (Manton and Gu 2001). In addition, there was a slight increase in the mean modified Charlson index score from 0.94 in 1984 to 1.07 in 1994.

Coefficients and standard errors from our estimation results are shown in tables 6-10 for models with all cvd patients, ischemic heart disease patients, stroke patients, heart failure patients and other circulatory disease patients. Each table includes a model with only survey year and demographic characteristics as well as a model with area-level relevant procedures, appropriate pharmaceutical use and interactions between year and time-invariant treatment covariates.

All-CVD 
In the all-cvd models, the average respondent from the 1994 survey was significantly less likely to be disabled and dead compared to the average respondent to the 1984 survey, when adjusting for only demographic and health status covariates (Table 6). When we include treatments covariates, the average respondent living in an area with average treatment rates in the 1994 survey was significantly less likely to experience disability and death at follow-up survey compared to the average respondent in an average area in 1984, but inclusion of treatment covariates moderated the associations. In particular, area-level use of treatments explains approximately $3.5 \%$ and $29 \%$ of the difference in disability and death outcomes, respectively, between the 1994 and 1984 cohorts. Relevant procedures were significantly associated with a decreased likelihood of death $(\mathrm{p}=0.044)$, but not disability $(\mathrm{p}=0.756)$, while all AMI treatments together were significantly associated with disability $(\mathrm{p}=0.001)$ and death $(\mathrm{p}=0.020)$.

Predicted event rates for all cvd patients in areas at the $10^{\text {th }}$ and $90^{\text {th }}$ percentiles are shown in Figures 5 and 6. For relevant procedures, the probability of death is lower at all time points for $90^{\text {th }}$ percentile areas, and due to increasing rates of procedure use, it decreases faster for the $90^{\text {th }}$ compared to $10^{\text {th }}$ percentile over time. When examining time invariant AMI treatment variables together, we find that the probability of disability declined 6 percentage points from $28 \%$ in 1984 to $22 \%$ in 1994 for the $90^{\text {th }}$ percentile and increased approximately 3 percentage points from $23 \%$ to $26 \%$ in $10^{\text {th }}$ percentile areas.

\section{Ischemic Heart Disease}

As described in more detail in (Stewart, Landrum et al. 2006), treatment covariates explain between 50 and $70 \%$ of the association between disability and death over time in the 
IHD cohort. Relevant procedures were significantly associated with death, but not disability, and pharmaceutical care was significantly associated with disability but not death.

\section{Stroke}

Stroke patients in 1994 were significantly less likely to experience disability and death compared to patients in the 1984 survey in the model with only demographic and health status covariates (Table 7). Including treatment covariates explains approximately $42 \%$ and $23 \%$ of the association between 1994 survey year and disability and death, respectively. The coefficient on 1994 survey year for disability is not statistically significant in the model with treatments, suggesting that in areas with average levels of treatment there were no significant declines in disability. The coefficient on 1994 survey year for death remains statistically significant, suggesting that additional factors are important in explaining the decreased probability of death in 1994 relative to 1984 .

Use of relevant procedures for stroke patients is significantly associated with lower likelihood of disability $(\mathrm{p}=0.010)$, but not with death $(\mathrm{p}=0.157)$. Use of AMI treatments measured at the HRR-level from the CCP data and increased use of warfarin and antithrombolytics measured at the state level are together significantly associated with death $(\mathrm{p}=$ $0.001)$ but not disability $(\mathrm{p}=0.175)$. These results are apparent in predicted outcome rates displayed in Figures 7 and 8. The predicted probability of disability for stroke patients in $90^{\text {th }}$ percentile areas of relevant procedures falls from $29 \%$ in 1984 to $25 \%$ in 1994 (?) and the probability of disability in $10^{\text {th }}$ percentile areas rises from $33 \%$ in 1984 to $36 \%$ in 1989 and back to $33 \%$ in 1994 (Figure 7). In areas at the $90^{\text {th }}$ percentile for AMI and stroke treatments, the probability of death declines from $48 \%$ in 1984 to $35 \%$ in 1989 and then increases to $40 \%$ by 
1994 (Figure 8). The trend is opposite in $10^{\text {th }}$ percentile areas, with the probability of death increasing from $43 \%$ in 1984 to $51 \%$ by 1989 and then decreasing to $42 \%$ by 1994 .

\section{Heart Failure and Arrhythmia}

Table 8 shows that the heart failure and arrhythmia patients in 1994 were significantly less likely to die by follow-up compared to patients in 1984 in the model with only demographic and health status covariates. Including treatment covariates strengthens the association between survey year and death, i.e. the average respondent in the average area is even less likely to die in 1994 compared to 1984. Relevant procedures for heart failure and arrhythmia are not associated with either disability $(\mathrm{p}=0.903)$ or death $(\mathrm{p}=0.574)$. Use of AMI treatments and evaluation of ejection fraction are significantly associated with disability $(\mathrm{p}=0.043)$ but not death $(\mathrm{p}=0.087)$. As expected based on estimation results, there is little difference in the probability of death and disability between $10^{\text {th }}$ and $90^{\text {th }}$ percentile areas of relevant procedures (Figure 9). In examination of the AMI and heart failure treatments (Figure 11), the probability of disability is higher in $90^{\text {th }}$ percentile areas in 1984 and 1989 compared to $10^{\text {th }}$ percentile areas. By 1994 , the probability of disability is much lower in the $90^{\text {th }}$ percentile areas (19\%) compared to the $10^{\text {th }}$ percentile (26\%).

\section{Other Circulatory Diseases}

In the model with demographic and health characteristics, circulatory disease patients in the 1994 survey were significantly less likely to be disabled and dead at follow-up compared to the 1984 survey (Table 9). When we include treatment covariates, we explain approximately $18 \%$ of the association between 1994 survey year and death, and the 1994 survey year coefficient 
on death is no longer statistically significant. The 1994 survey year coefficient on disability becomes more negative with the inclusion of treatment variables, i.e. -0.38 vs. -0.37 , and remains statistically significant. Relevant procedures are not associated with either disability or death in this model. AMI treatments are associated with disability $(\mathrm{p}=0.044)$, but not with death $(\mathrm{p}=0.146)$. Predicted outcomes rates by AMI treatments show that the probability of disability declines by 13 percentage points in $90^{\text {th }}$ percentile areas from $32 \%$ to $19 \%$ and increases by 8 percentage points from $25 \%$ to $33 \%$ in $10^{\text {th }}$ percentile areas (Figure 12).

\section{Interpreting the Results}

Use of effective treatments contributed to the decline in disability and death among cardiovascular disease patients. The association between treatment use and reduced disability and death was strongest in the ischemic heart disease model, explaining over half of the decline in disability for the 1994 cohort and 65-70\% of the decline in mortality for the 1989 and 1994 cohorts. With the exception of the stroke model, use of AMI treatments was significantly associated with declining disability. In the all-CVD and stroke models, AMI treatments were significantly associated with reductions in mortality. Increased use of relevant procedures resulted in lowered disability among stroke patients as well as lowered death in the all-cvd and ischemic heart disease models.

Improved medical treatment after an acute cardiovascular event resulted in improved survival and reductions in disability. It may also affect medical spending. While we cannot do a complete evaluation of the impact of these changes, we can provide some information. We begin with the change in quality-adjusted life expectancy. To consider how reductions in disability in one year translate into long-term changes in quality-adjusted life expectancy, we 
estimate regression models for future survival and disability status as a function of disability in a base year. For a cohort in year t, we estimate linear probability models of the form:

$$
\operatorname{Pr}[\text { Alive in year } \mathrm{t}+\mathrm{k}]_{\mathrm{i}}=\mathbf{X}_{\mathrm{i}, \mathrm{t}} \boldsymbol{\beta}+\gamma \text { Disability }_{\mathrm{i}, \mathrm{t}}+\mathrm{e}_{\mathrm{i}, \mathrm{t}}
$$

The coefficient $\gamma$ indicates how changes in disability in year $t$ affect long-term health outcomes. $\mathrm{X}_{\mathrm{i}, \mathrm{t}}$ is a set of demographic and health status variables. The identifying assumption in equation (3) is that people who are not disabled because of medical treatment are subsequently equivalent in their health to those who never had an incident. This may or may not be the case. If this is not true, and survivors of events are less healthy, conditional on disability status, we will overstate the benefits of reductions in disability. Thus, one should properly view these estimates as an upper bound on the impact of medical interventions to reduce disability.

Figure 13 shows the survival rate by year, conditional on disability status in the base survey year. We report the results for the 10 years after the survey for the 1989 cohort, and the five years after the survey for the 1994 cohort due to data limitations on long-term follow-up. Not surprisingly, survival for the disabled is below that for the non-disabled, by a large margin. The difference is about 20 percentage points, and remains at that level throughout the decade. To forecast mortality beyond the 10 year observation window, we assume that the mortality hazard estimated in 1997-99 prevails in all subsequent years. Making this assumption, we estimate that those not disabled in 1989 have an average life expectancy of 7.8 years while those disabled in 1989 were expected to live only another 5.1 years on average (Table 11).

The above calculation, does not account for the difference in subsequent disability in the next decade. Table 10 shows the disability rate for the 1989 cohort in the 1994 and 1999 
surveys, and the disability rate for the 1994 cohort in 1999. In each case, we condition disability status on being alive at the end date. Seventy-nine percent of people who were disabled in 1989 and still alive in 1994 were also disabled in 1994, compared to 31 percent of those not disabled in 1989. This pattern repeats itself in 1999, and is true for the 1994 cohort as well.

To estimate quality-adjusted life expectancy, we interpolate disability rates between 1989 and 1994, and 1994 and 1999. In each case, we assume that disability rates change at a common rate each year of the interval. We also extrapolate disability rates after 1999 using the annual change between 1994 and 1999. As a rough approximation, we assume that 1 year in a disabled state is equivalent to 0.5 quality-adjusted life years.

As the second row of table 11 shows, quality-adjusted life expectancy is lower in each case than is life expectancy, but the difference between the disabled and non-disabled is similar to the unadjusted estimates. The increase in quality-adjusted life expectancy associated with not being disabled is 3.7 years.

The value of this improvement in life expectancy depends on the value of a year of life. Following a substantial recent literature (Viscusi and Aldy 2003), we assume that a year of life in good health is worth $\$ 100,000$ (in 1992 dollars). We also assume that future values are discounted at a 3 percent real rate of interest. Using these assumptions, we estimate the value of disability prevention to be $\$ 316,000$.

These benefits need to be weighed against the cost of reducing disability. These costs have two parts. The first is the initial treatment cost that led to the reduction in disability. To measure these costs, we use data on hospitalization spending for the 1989 cohort in the year after the CVD admission ${ }^{9}$. The one year interval is relatively common in studying the acute treatment

\footnotetext{
${ }^{9}$ By definition all participants in the 1989 cohort had at least one CVD admissions between 1984 and 1989. We averaged costs across all CVD hospitalizations for respondents with multiple relevant hospitalizations.
} 
for cardiovascular disease (Cutler and McClellan 2001; Skinner, Staiger et al. 2006). The limitation to hospital costs is because only those data are reliable prior to 1991 . We inflated all costs to a common year of 1992 using the implicit GDP Price Deflator (Economic Report of the President 1997). We estimate that in the year after the CVD event, hospital spending averages $\$ 8,610$ for patients who do not receive relevant procedures and $\$ 16,332$ for patients receiving relevant procedures.

Although treatment costs are approximately twice as high for respondents receiving appropriate treatments, these costs may be offset by lower yearly spending in subsequent years among survivors. A previous study of 1982 and 1984 NLTCS respondents found annual per capita spending by Medicare for respondents without any ADL or IADL limitations was approximately $\$ 3,275$, compared to $\$ 7,400$ for respondents with at least 4 ADL and 5 IADL impairments and $\$ 13,100$ for institutionalized respondents. These data suggest that the costs of intensive medical treatments that prevent or delay disability may be offset by lower annual average spending among healthier beneficiaries.

More recent studies using the Medicare Current Beneficiary Survey found similar lifetime spending between non-disabled and disabled 70 year olds (Lubitz, Cai et al. 2003), but life expectancy was approximately 2.7 years longer among the non-disabled (Lubitz, Cai et al. 2003). This provides further evidence that average annual spending may be lower among the non-disabled relative to the disabled. However, another recent study found spending on the nondisabled is growing faster than spending on the disabled (Chernew, Goldman et al. 2005). Whether increased spending on intensive medical care treatments, such as those for cardiovascular disease, continues to increase life expectancy and reduce average annual yearly spending among the non-disabled relative to the disabled will require further investigation. 


\section{Conclusions}

Examining disability associated with cardiovascular disease leads to several important results. Reduced disability associated with cardiovascular disease accounts for a significant part of the total reduction in disability - between 19 and 22 percent. The evidence suggests that improvements in medical care, including both increased use of relevant procedures and pharmaceuticals, led to a significant part of this decline. Areas with higher use experienced substantial reductions in mortality and disability.

While precise data on the implications of reduced disability are lacking, the possible impact of disability reductions is staggering. We estimate that preventing disability after an acute event can add as much as 3.7 years of quality-adjusted life expectancy, or perhaps $\$ 316,000$ of value. The cost of this change is much smaller. The initial treatment costs range from $\$ 8,610$ to $\$ 16,332$, depending on procedure use. Further, recent cost analyses reported that annual Medicare spending was lower for the non-disabled compared to the disabled, which suggests that higher treatment costs may be offset by lower future spending among a more healthy population. By virtually any measure, therefore, medical technology after acute cardiovascular episodes is worth the cost.

The major issue raised by our results is whether these conclusions extend to other conditions. Disability reductions are complex, and will certainly involve medical as well as nonmedical factors. Sorting these out for other conditions is a high priority for future research. 


\section{References}

Adams, H., R. Adams, et al. (2005). "Guidelines for the early management of patients with ischemic stroke. 2005 Guidelines Update: A scientific statement from the stroke council of the American Heart Association/American Stroke Association." Stroke 36: 916-921.

American Heart Association (2006). http://www.americanheart.org/presenter.jhtml?identifier=1200000. Last accessed April 12, 2006.

Antman, E. M., D. T. Anbe, et al. (2004). "ACC/AHA guidelines for the management of pateints with ST-elevation myocardial infarction: executive summary: a resport of the ACC/AHA task force on practice guidelines (committee to revise the 1999 guidelines on the management of patients with acute myocardial infarction)." J Am Coll Cardiol 44: 671719.

Appelros, P., I. Nydevik, et al. (2003). "Poor outcome after first-ever stroke: Predictors for death, dependency, and recurrent stroke within the first year." Stroke 34: 122-126.

Borkon, A. M., G. F. Muehlebach, et al. (2002). "A comparison of the recovery of health status after percutaneous coronary intervention and coronary artery bypass." Ann Thorac Surg 74: 1526-1530.

Braunwald, E., E. M. Antman, et al. (2002). "ACC/AHA 2002 guideline update for the management of patients iwth unstable angina and non-ST segment elevation myocardial infaction: a report of the American College of Cardiology / American Heart Association task force on practice guidelines (Committee on the management of patients with unstable angina)." Available at: http://www.acc.org/clinical/guidelines/unstable/incorporated/index.htm. Last accessed June 12, 2005.

Chernew, M. E., D. P. Goldman, et al. (2005). "Disability and health care spending among Medicare beneficiaries." Health Affairs 24(2): W5-R42-W5-R51.

Clark, W. M., S. Wissman, et al. (1999). "Recombinant tissue-type plasminogen activator (alteplase) for ischemic stroke 3 to 5 hours after symptom onset." JAMA 282(21): 20192026.

Crimmins, E. M., M. D. Hayward, et al. (1994). "Changing mortality and morbidity rates and the health status and life expectancy of the older population." Demography 31(1): 159-175.

Crimmins, E. M., Y. Saito, et al. (1989). "Changes in life expectancy and disability-free life expectancy in the United States." Population and Development Review 15(2): 235-267.

Cutler, D. M. and S. Kadiyala (2003). The Return to Biomedical Research: Treatment and Behavioral Effects. Measuring the Gains from Medical Research: An Economic Approach. K. M. M. a. R. H. Topel. Chicago, University of Chicago Press.

Cutler, D. M. and M. McClellan (2001). "Is technological change in medicine worth it?" Health Affairs 20(5): 11-29.

Deyo, R. A., D. C. Cherkin, et al. (1992). "Adapting a clinical comorbidity index for use with ICD-9-CM administrative databases." J Clin Epidemiol 45(6): 613-619.

Economic Report of the President (1997). Washington, United States Government Printing Office: http://www.gpoaccess.gov/usbudget/fy98/pdf/erp.pdf, Last accessed April 12, 2006. 
Fisher, E. S., D. E. Wennberg, et al. (2003). "The implications of regional variations in Medicare spending. Part 2: Health outcomes and satisfaction with care." Ann Intern Med 138: 288298.

Fisher, E. S., D. E. Wennberg, et al. (2003). "The implications of regional variations in Medicare spending. Part I: The conent, quality andn accessibility of care." Ann Intern Med 138: 273-287.

Freemantle, N., J. Cleland, et al. (1999). "B blockade after myocardial infarction: systematic review and meta regression analysis." BMJ 318: 1730-1737.

Glader, E.-L., B. Stegmayr, et al. (2003). "Sex differences in management and outcome after stroke: A Swedish national perspective." Stroke 34: 1970-1975.

Gottlieb, S. S., R. J. McCarter, et al. (1998). "Effect of beta blockade on mortality among highrisk and low-risk patients after myocardial infarction." N Engl J Med 339(8): 489-497.

Group, N. r.-P. S. S. (1995). "Tissue plasminogen activator for acute ischemic stroke." NEJM 333(24): 1581-1587.

Heidenreich, P. A. and M. McClellan (2001). "Trends in treatment and outcomes for acute myocardial infarction: 1975-1995." Am J Med 110: 165-174.

Hennekens, C. H., C. M. Albert, et al. (1996). "Adjunctive drug therapy of acute myocardial infarction - evidence from clinical trials." N Engl J Med 335(22): 1660-1667.

Henon, H., O. Godefroy, et al. (1995). "Early predictors of death and disability after acute cerebral ischemic event." Stroke 26: 392-398.

Hlatky, M. A., W. J. Rogers, et al. (1997). "Medical care costs and quality of life after randomization to coronary angioplasty or coronary bypass surgery." $\mathrm{N}$ Engl J Med 336: 92-99.

Jencks, S. F., E. D. Huff, et al. (2003). "Change in the quality of care delivered to Medicare beneficiaries, 1998-1999 and 2000-2001." JAMA 289: 305-312.

Kattainen, A., R. A., et al. (2004). "Secular changes in disability among middle-aged and elderly Finns with and without coronary heart disease from 1978-1980 to 2000-2001." Ann Epidemiol 14: 479-485.

Krumholz, H. M., M. J. Radford, et al. (1996). "Aspirin for secondary prevention after acute myocardial infarction in the elderly: Prescribed use and outcomes." Ann Intern Med 124: 292-298.

Krumholz, H. M., M. J. Radford, et al. (1995). "Aspirin in the treatment of acute myocardial infarction in elderly Medicare beneficiaries." Circulation 92(2841-7).

Krumholz, H. M., M. J. Radford, et al. (1998). "National use and effectiveness of [small beta]blockers for the treatment of elderly patients after acute myocardial infarction: National cooperative cardiovascular project." JAMA 280(7): 623-629.

Landrum, M. B. and K. A. Stewart (2006). "Clinical pathways to disability: An analysis of major clinical contributors to disability in the elderly." Submitted for publication.

Lubitz, J., L. Cai, et al. (2003). "Health, life expectancy and health care spending among the elderly." NEJM 349: 1048-55.

Manton, K. G., L. S. Corder, et al. (1993). "Estimates of change in chronic disability and institutional incidence and prevalence rates in the U.S. elderly population from the 1982, 1984 and 1989 National Long Term Care Survey." Journal of Gerontology 48(4): S153S166.

Manton, K. G., L. S. Corder, et al. (1997). "Chronic disability trends in elderly United States populations: 1982-1994." Proc Natl Acad Sci 94: 2593-2598. 
Manton, K. G. and X. Gu (2001). "Changes in the prevalence of chronic disability in the United States black and nonblack population above age 65 from 1982 to 1999." Proceedings of the National Academy of Sciences of the United States of America 98(11): 6354-6359.

Manton, K. G., E. Stallard, et al. (1997). "Changes in the age dependence of mortality and disability: cohort and other determinants." Demography 34(1): 135-57.

Marciniak, T. A., E. F. Ellerbeck, et al. (1998). "Improving the quality of care for Medicare patients with acute myocardial infarction: Results from the cooperative cardiovascular project." JAMA 279(17): 1351-1357.

McGovern, P. G., D. R. Jacobs, et al. (2001). "Trends in acute coronary heart disease mortality, morbidity and medical care from 1985 through 1997: The Minnesota Heart Study." Circulation 104: 19-24.

McGovern, P. G., J. S. Pankow, et al. (1996). "Recent trends in acute coronary heart disease: Mortality, morbidity, medical care and risk factors." N Engl J Med 334(884-890).

O'Connor, G. T., H. B. Quinton, et al. (1999). "Geographic variation in the treatment of acute myocardial infarction: The Cooperative Cardiovascular Project." JAMA 281(7): 627-633.

Pfisterer, M., P. Buser, et al. (2003). "Outcome of elderly patients with chronic symptomatic coronary artery disease with an invasive vs optimised medical treatment strategy: One year results of the randomized TIME trial." JAMA 289: 1117-1123.

Pocock, S. J., R. A. Henderson, et al. (2000). "Quality of life after coronary angioplasty or continued medical treatment for angina: Three-year follow-up in the RITA-2 trial." J Am Coll Cardiol 35: 907-914.

Pohjasvaara, T., T. Erkinjuntti, et al. (1997). "Comparison of stroke features and disability in daily life in patients with ischemic stroke aged 55 to 70 and 71 to 85 years." Stroke 28: 729-735.

Prencipe, M., C. Ferretti, et al. (1997). "Stroke, disability, and dementia." Stroke 28: 531-536.

Rogers, W. J., J. Coggin, et al. (1990). "Ten-year follow-up of quality of life in patients randomized to receive medical therapy or coronary artery bypass graft surgery: The coronary artery surgery study (CASS)." Circulation 82: 1647-1658.

Rosamond, W. D., L. E. Chambless, et al. (1998). "Trends in the incidence of myocardial infarction and in mortality due to coronary heart disease, 1987-1994." N Engl J Med 339(13): 861-867.

Shlipak, M. G., W. S. Browner, et al. (2001). "Comparison of the effects of angiotensin converting-enzyme inhibitors and beta blockers on survival in elderly patients with reduced left ventricular function after myocardial infarction." Am J Med 110: 425-433.

Singer, B. H. and K. G. Manton (1998). "The effects of health changes on projections of health service needs for the elderly population of the United States." Proceedings of the National Academy of Sciences of the United States of America 95(26): 15618-22.

Skinner, J. S., D. O. Staiger, et al. (2006). "Is technological change in medicine always worth it? The case of acute myocardial infarction." Health Affairs 7 February 2006: W34-W47.

Soumerai, S. B., T. J. McLaughlin, et al. (1997). "Adverse outcomes of underuse of betablockers in elderly survivors of acute myocardial infarction." JAMA 277(2): 115-121.

Stewart, K. A., M. B. Landrum, et al. (2006). "Improved Treatment for Ischemic Heart Disease and Disability and Death in the Elderly." Draft.

Strauss, W. E., T. Fortin, et al. (1995). "A comparison of quality of life scores in patients with angina pectoris after angioplasty compared with after medical therapy." Circulation 92: 1710-1719. 
Stukel, T. A., F. L. Lucas, et al. (2005). "Long-term outcomes of regional variations in intensity of invasive vs medical management of Medicare patients with acute myocardial infarction." JAMA 293: 1329-1337.

Sytkowski, P. A., R. B. D'Agostino, et al. (1996). "Sex and time trends in cardiovascular disease incidence and mortality: the Framingham Heart Study, 1950-1989." Am J Epidemiol 143(4): 338-350.

Viscusi, W. K. and J. E. Aldy (2003). "The Value of a Statistical Life: A Critical Review of Market Estimates Throughout the World." Journal of Risk and Uncertainty 27(1): 5-76.

Vitagliano, G., J. P. Curtis, et al. (2004). "Association between functional status and use and effectiveness of beta-blocker prophylaxis in elderly survivors of acute myocardial infarction." J Am Geriatr Soc 52: 496-501.

Waidmann, T. A., J. Bound, et al. (1995). "The illusion of failure: Trends in the self-reported health of the U.S. elderly." The Milbank Quarterly 73(2): 253-287.

Zhu, L., L. Fratiglioni, et al. (1998). "Association of stroke with dementia, cognitive impairment, and functional disability in the very old: A population-based study." Stroke 29: 20942099. 
Figure 1. Share of Population 70+ Who Are Disabled

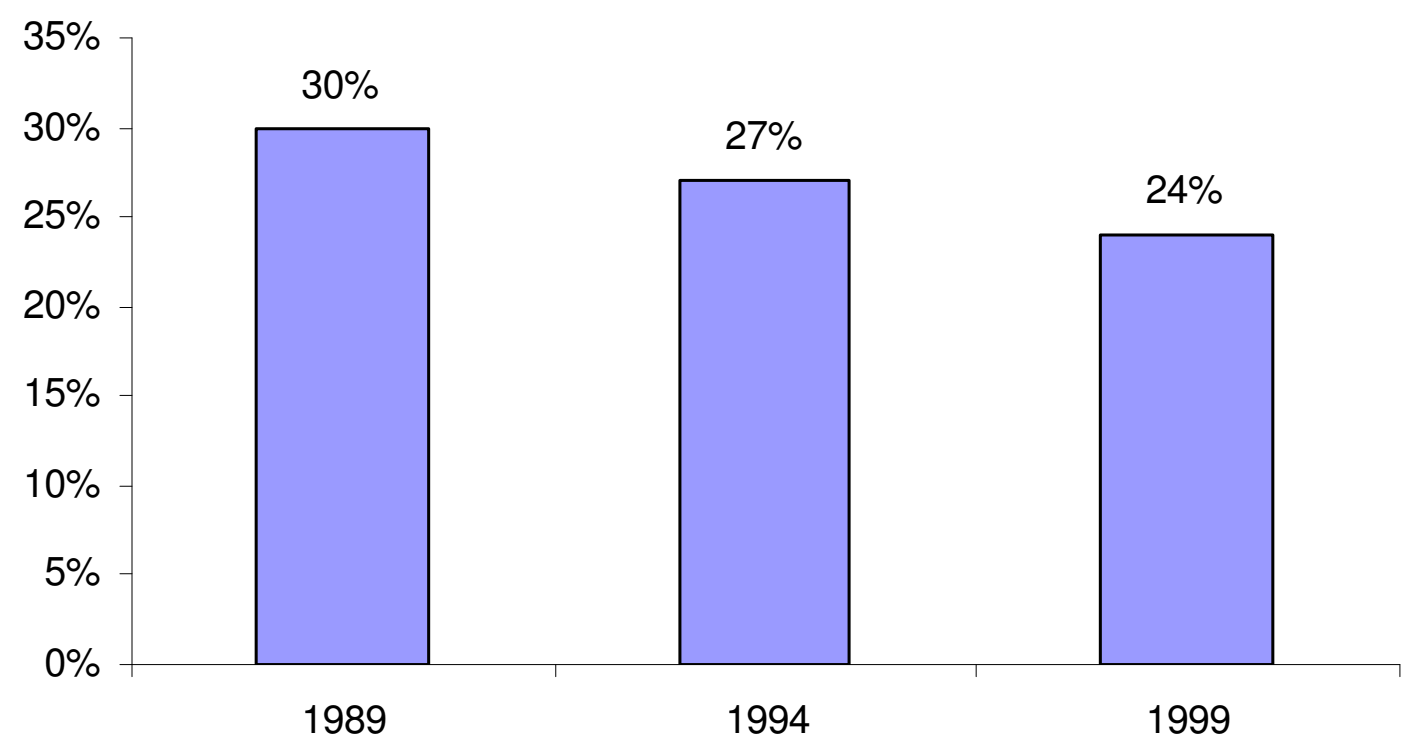

Note: Disability is defined as any difficulty conducting Activities of Daily Living or Instrumental Activities of Daily Living without help. 
Figure 2. Clinical Conditions for People age 70+ with Cardiovascular Disease

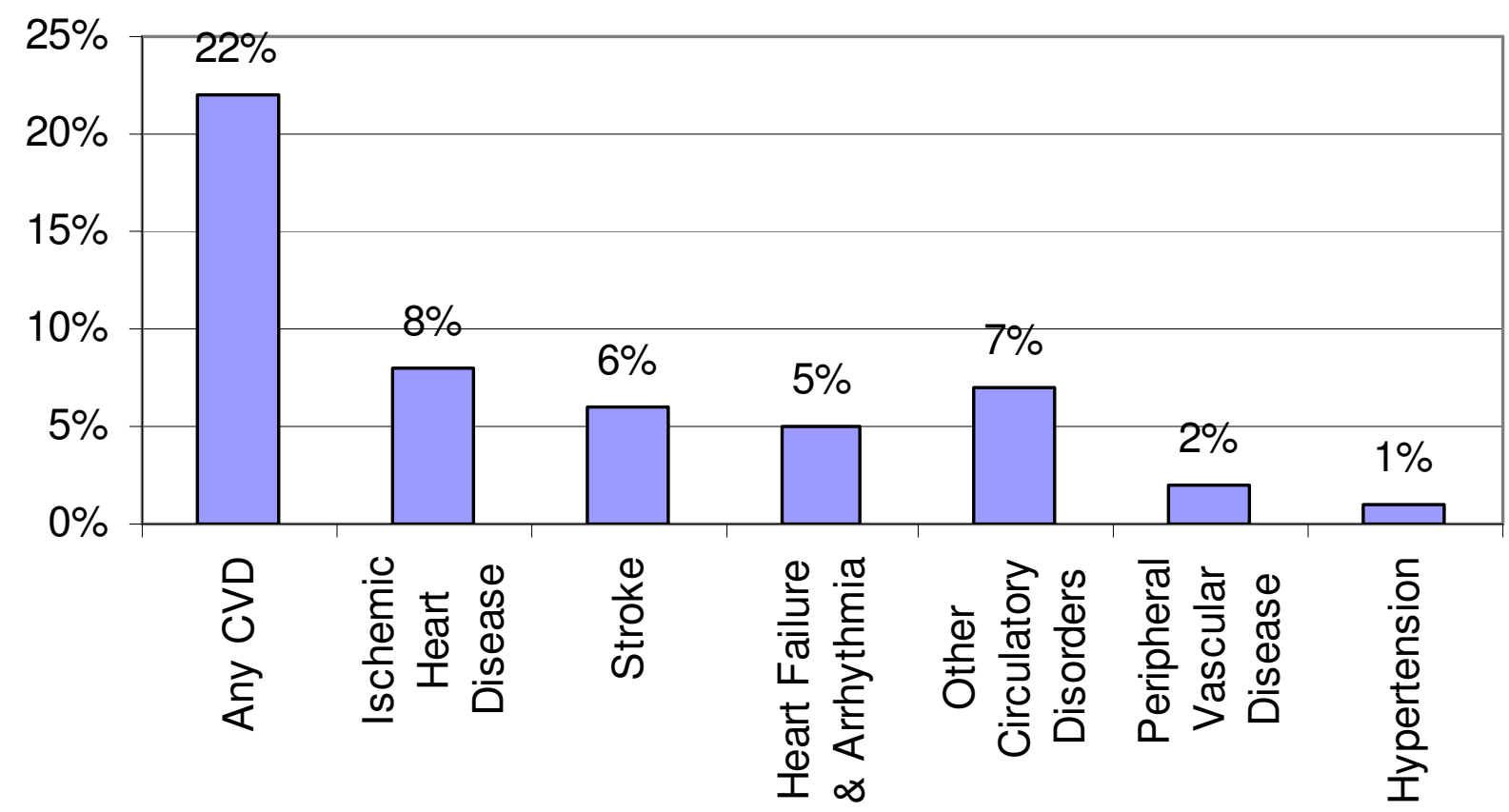

Note: The sample is NLTCS survey respondents with at least 1 CVD hospitalization in the 5 years prior to the survey, for all 3 survey years pooled. 
Table 1. Most Disabling Conditions*

\section{Condition}

Chronic renal failure

Dementia \& organic brain diseases

Paralysis, Parkinsons's, etc.

Hip \& pelvic fracture

Acute renal failure \& insufficiency

Other metabolic \& immunity disorders

Other blood diseases

Respiratory failure \& insufficiency

Anemia

Diabetes

Thyroid disorders

Stroke

Infectious diseases

Respiratory diseases

Depression

Peripheral vascular disease

Composite category

Musculoskeletal disorders

Heart failure \& arrhythmia

Chronic obstructive pulmonary diseases $\&$ related diseases

Other mental disorders

Glaucoma \& cataract

Hypertension

Gastrointestinal disease

Arthritis \& arthropathy

Circulatory diseases

Colorectal \& lung cancer

Back/neck pain

Ischemic heart disease

Genitourinary diseases

Other cancers

Breast \& prostate cancer

\section{$\%$ disabled}

88.9

83.1

82.5

80.2

68.1

67.0

66.5

66.5

65.9

64.1

59.9

59.5

59.2

56.8

56.2

55.4

54.8

53.2

51.5

51.0

49.9

48.8

48.4

45.2

45.0

42.0

40.0

39.2

38.7

38.7

37.6

28.9
Rank

1

2

3

4

5

6

7

8

9

10

11

12

13

14

15

16

17

18

19

20

21

22

23

24

25

26

27

28

29

30

31

32

* Analyses conducted using 1989 cohort, and based on primary hospitalization diagnosis codes in the proceeding 5 years. Composite category includes hospitalizations for any diagnoses other than the 31 specific categories above. 
Figure 3. Probability of Being Disabled Because of Cardiovascular Disease

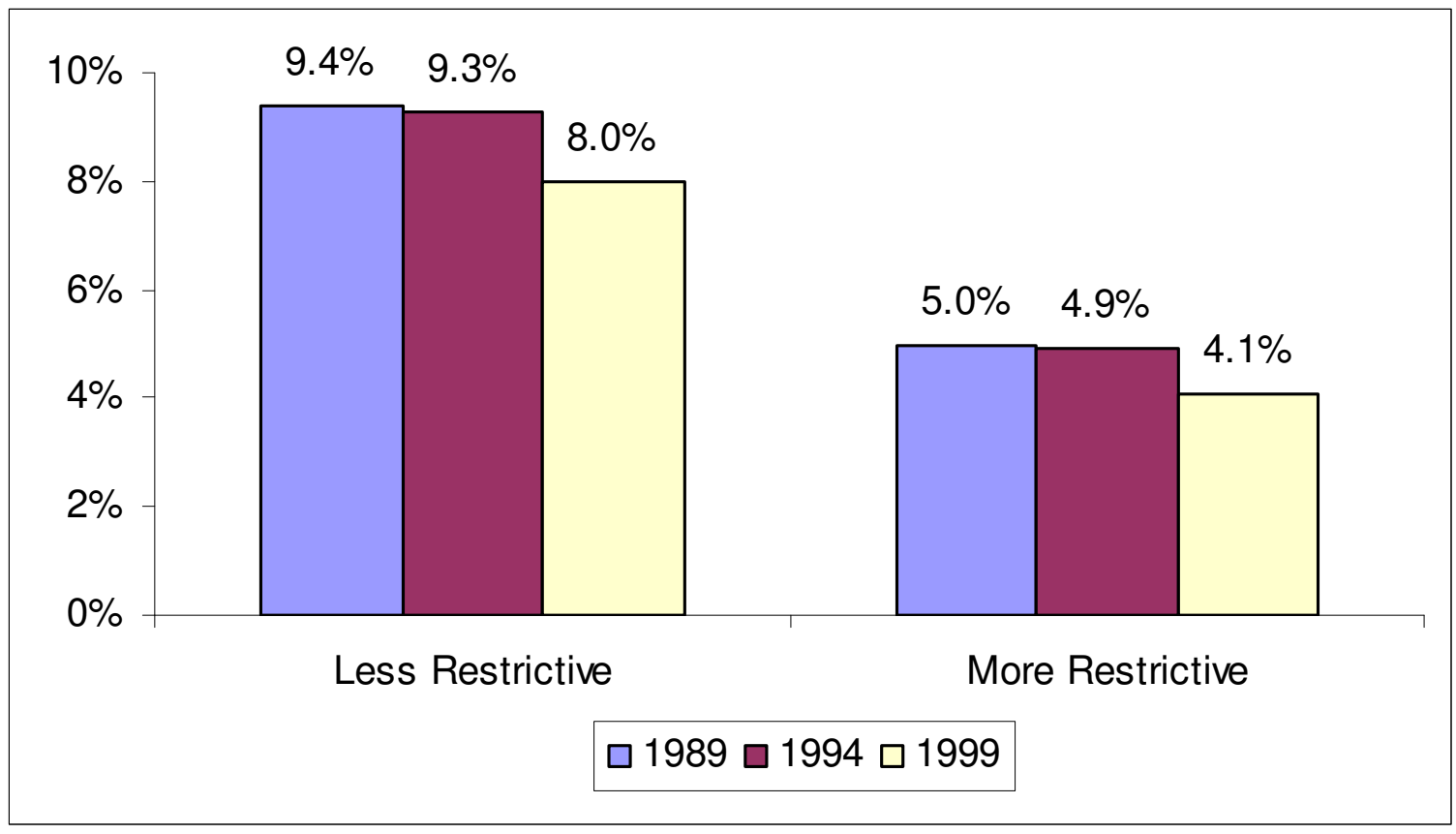

Note: Cross-sectional analyses based on hospitalizations in the 5 years prior to the survey. 


\begin{tabular}{|l|c|c|c|c|}
\hline Table 2: Decomposing Changes in Cardiovascular Disease Disability \\
\hline & $1984-1989$ & $1989-1994$ & $1994-1999$ & $\begin{array}{c}\text { Change, } \\
1984-89 \text { to } \\
1994-99\end{array}$ \\
\hline & & & & $-0.2 \%$ \\
\hline Share with CVD event & $26.5 \%$ & $29.0 \%$ & $26.3 \%$ & 4.3 \\
\hline Share with an event who survive & 57.2 & 58.4 & 61.5 & -8.2 \\
\hline $\begin{array}{l}\text { Share of survivors who are } \\
\text { disabled }\end{array}$ & 47.6 & 43.7 & 39.4 & \\
\hline Source: Authors tabulations from the National Long-Term Care Survey. \\
\hline
\end{tabular}

Note: Data are based on respondents with a CVD hospitalization in between survey waves, and known health status at the second survey. Weights were adjusted to the age and sex distribution of the 1999 NLTCS survey population, and account for unknown follow-up status at the second survey. 
Figure 4. Likelihood of reporting disability among respondents with specific cardiovascular disease events in the 6 months prior to survey

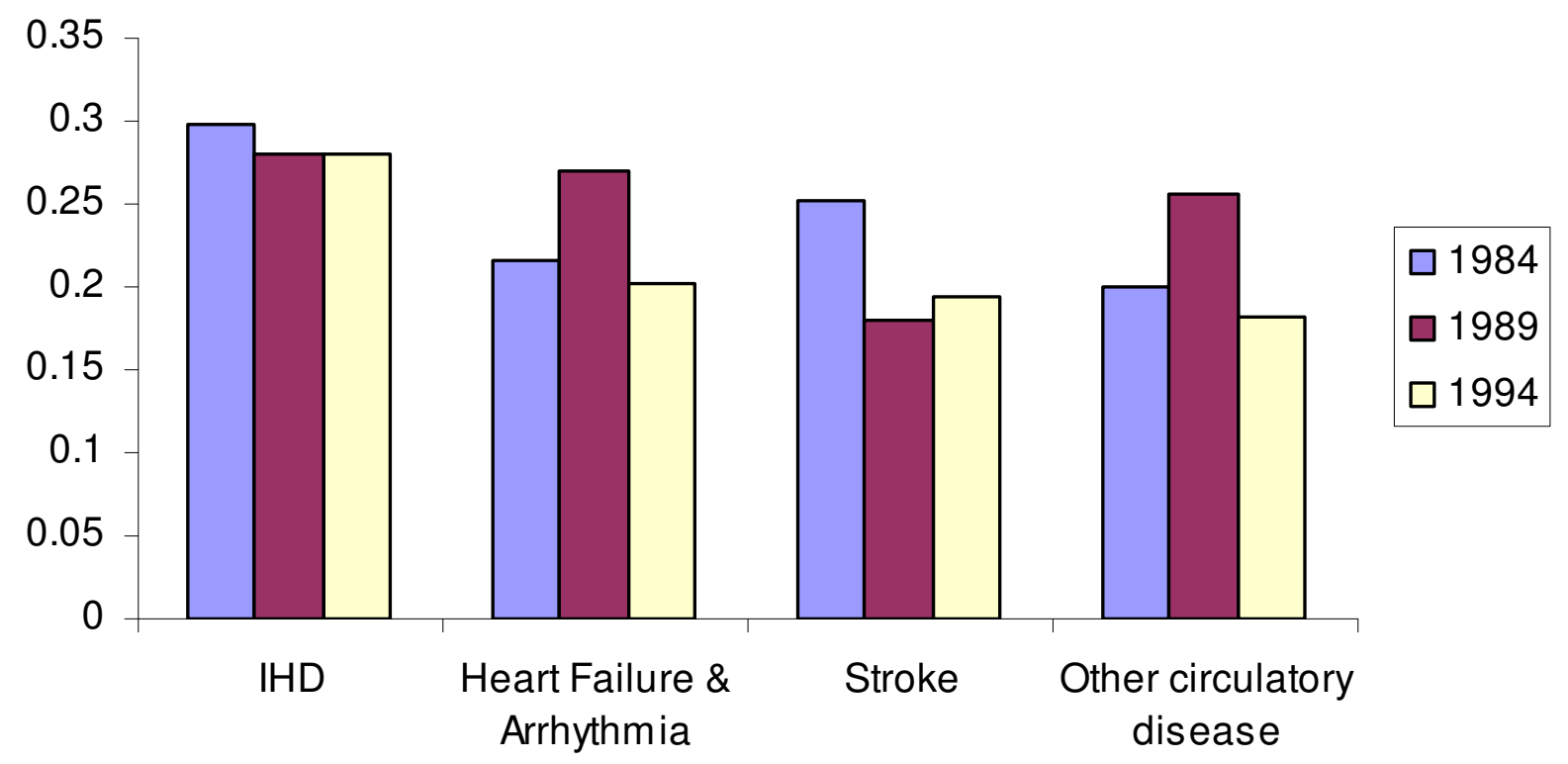




\begin{tabular}{|l|l|}
\hline \multicolumn{2}{|c|}{ Table 3: Relevant Procedures for Cardiovascular Disease Admissions } \\
\hline Condition & Appropriate procedures (CPT-4 Code) \\
\hline Stroke & Incision, excision, and occlusion of vessels (38) \\
\hline Hypertension & --- \\
\hline Ischemic heart disease & $\begin{array}{l}\text { Operations on vessels of heart (36) } \\
\text { Other operations on heart and pericardium (37) }\end{array}$ \\
\hline Heart failure and arrhythmia & $\begin{array}{l}\text { Other operations on heart and pericardium (37) } \\
\text { Conversion of cardiac rhythm (99) }\end{array}$ \\
\hline Peripheral vascular disease & $\begin{array}{l}\text { Incision, excision, and occlusion of vessels (38) } \\
\text { Operation operations on vessels (39) } \\
\text { Other procedures on musculoskeletal system (84) }\end{array}$ \\
\hline Other circulatory diseases & $\begin{array}{l}\text { Operations on valves and septa of heart (35) } \\
\text { Other operations on heart and pericardium (37) } \\
\text { Incision, excision, and occlusion of vessels (38) }\end{array}$ \\
\hline
\end{tabular}




\begin{tabular}{|l|c|c|c|}
\hline \multicolumn{4}{|l|}{ Table 4: Average Rates of Procedures and Pharmaceuticals } \\
\hline Measure & $1984-1989$ & $1989-1994$ & $1994-1999$ \\
\hline $\begin{array}{l}\text { Share of people receiving appropriate } \\
\text { procedure, \% (SD) }\end{array}$ & $21.1(0.4)$ & $26.1(0.5)$ & $34.2(0.6)$ \\
\hline By specific conditions & & & \\
\hline Ischemic Heart Disease & $22.6(0.9)$ & $33.2(1.0)$ & $47.9(1.3)$ \\
\hline Stroke & $13.0(0.8)$ & $17.1(0.9)$ & $24.8(1.0)$ \\
\hline Heart Failure & $11.3(0.6)$ & $11.9(0.8)$ & $14.2(0.9)$ \\
\hline Other Circulatory Diseases & $29.7(1.1)$ & $32.5(1.2)$ & $43.0(1.3)$ \\
\hline Beta-blockers & --- & $50.7(1.0)$ & --- \\
\hline Reperfusion & & $67.1(0.8)$ & \\
\hline Aspirin & & $76.4(0.6)$ & \\
\hline Ace-inhibitors & & $60.0(0.6)$ & \\
\hline
\end{tabular}

Note: Based on respondents with a CVD hospitalization between survey waves. The procedure figures are the averages across HRRs, consistent with the CCP data. 
Table 5. Demographic characteristics of CVD cohort, by year of baseline survey*

\begin{tabular}{|l|c|c|c|}
\hline & $\mathbf{1 9 8 4}$ & $\mathbf{1 9 8 9}$ & $\mathbf{1 9 9 4}$ \\
& $\begin{array}{c}\mathrm{N}=4,146 \\
\mathrm{wN}=6,403,326\end{array}$ & $\begin{array}{c}\mathrm{N}=3,671 \\
\mathrm{wN}=7,935,884\end{array}$ & $\begin{array}{c}\mathrm{N}=3,676 \\
\mathrm{wN}=7,723,454\end{array}$ \\
\hline Age groups, \% & & & 21.0 \\
\hline $65-69$ & 20.0 & 21.6 & 22.7 \\
\hline $70-74$ & 24.8 & 24.3 & 17.0 \\
\hline $75-79$ & 23.2 & 23.4 & 15.2 \\
\hline $80-84$ & 17.2 & 16.7 & 45.4 \\
\hline $85+$ & 14.8 & 14.1 & 8.8 \\
\hline Male, \% & 45.0 & 45.7 & 51.3 \\
\hline & 8.0 & 7.9 & 36.7 \\
\hline Non-white, \% & & & 9.5 \\
\hline Marital status, \% & 31.3 & 31.1 & 2.4 \\
\hline Married & 8.1 & 10.0 & 25.9 \\
\hline Widowed & 1.1 & 1.1 & $1.07(0.02)$ \\
\hline $\begin{array}{l}\text { Divorced, Separated } \\
\text { or Single }\end{array}$ & 32.2 & 30.0 & \\
\hline $\begin{array}{l}\text { Unknown marital } \\
\text { status }\end{array}$ & & $1.04(0.02)$ & \\
\hline & & & \\
\hline $\begin{array}{l}\text { Disabled at baseline } \\
\text { survey, \% }\end{array}$ & & & \\
\hline & & & \\
\hline $\begin{array}{l}\text { Modified Charlson } \\
\text { comorbidy index** } \\
\text { mean (SD) }\end{array}$ & $0.94(0.02)$ & & \\
\hline
\end{tabular}

*Estimates adjusted to the age and sex distribution of the 1999 population of Medicare beneficiaries

**Hospitalizations for cardiovascular disease events were excluded from the Charlson index. 
Table 6. All CVD: Multinomial Regression Models for Health Status Outcome 5 Years after Baseline Survey ***

\begin{tabular}{|c|c|c|c|c|}
\hline & \multicolumn{2}{|c|}{ Model 1: } & \multicolumn{2}{|c|}{ Model 2: } \\
\hline Coefficients (SEs) & Disability & Death & Disability & Death \\
\hline Year89 & $-0.00(0.09)$ & $-0.01(0.08)$ & $-0.00(0.09)$ & $0.02(0.08)$ \\
\hline Year94 & $-0.28(0.08) \dagger$ & $-0.31(0.08) \dagger$ & $-0.27(0.10) \dagger$ & $-0.22(0.09) \#$ \\
\hline Reperfusion & - & - & $0.01(0.01) \#$ & $0.00(0.01)$ \\
\hline $\begin{array}{l}\text { Reperfusion * } \\
\text { Year89 }\end{array}$ & - & - & $-0.02(0.01) \#$ & $-0.00(0.01)$ \\
\hline $\begin{array}{l}\text { Reperfusion * } \\
\text { Year94 }\end{array}$ & - & - & $-0.03(0.01) \dagger$ & $-0.01(0.01)$ \\
\hline Beta Blockers & - & - & $-0.00(0.01)$ & $0.00(0.00)$ \\
\hline $\begin{array}{l}\text { Beta Blocker * } \\
\text { Year89 }\end{array}$ & - & - & $-0.00(0.01)$ & $-0.01(0.01)$ \\
\hline $\begin{array}{l}\text { Beta Blocker * } \\
\text { Year94 }\end{array}$ & - & - & $-0.01(0.01)$ & $-0.02(0.01) \dagger$ \\
\hline Aspirin & - & - & $0.00(0.01)$ & $0.00(0.01)$ \\
\hline Aspirin * Year89 & - & - & $-0.01(0.01)$ & $-0.02(0.01)$ \\
\hline Aspirin * Year94 & - & - & $0.00(0.01)$ & $-0.00(0.01)$ \\
\hline Ace-inhibitors & - & - & $0.01(0.01) \#$ & $0.01(0.01)$ \\
\hline $\begin{array}{l}\text { Ace-inhibitor } \\
* \text { Year89 }\end{array}$ & - & - & $-0.01(0.01)$ & $-0.00(0.01)$ \\
\hline $\begin{array}{l}\text { Ace-inhibitor } \\
\text { *Year94 }\end{array}$ & - & - & $0.00(0.01)$ & $0.00(0.01)$ \\
\hline Relevant procedures & - & - & $-0.00(0.00)$ & $-0.01(0.00) \#$ \\
\hline \multicolumn{5}{|l|}{ F-tests } \\
\hline $\begin{array}{l}\text { Disability and Death: } \\
\text { All CCP variables }\end{array}$ & & & $\mathrm{P}=0.0008$ & $\mathrm{P}=0.0203$ \\
\hline $\begin{array}{l}\text { Overall: All CCP } \\
\text { variables }\end{array}$ & & & \multicolumn{2}{|c|}{$\mathrm{P}=0.0025$} \\
\hline \multicolumn{5}{|l|}{ Model Statistics } \\
\hline $\mathrm{N}$ & \multicolumn{2}{|c|}{11491} & \multicolumn{2}{|c|}{11491} \\
\hline F-test & \multirow{2}{*}{\multicolumn{2}{|c|}{$\begin{array}{c}57.27 \\
<0.0001\end{array}$}} & \multicolumn{2}{|c|}{$\begin{array}{c}43.54 \\
<0.0001\end{array}$} \\
\hline $\mathrm{P}$-value & & & & 001 \\
\hline
\end{tabular}

*Models also adjust for age and sex interactions, marital status, race (white vs. other), Charlson co-morbidity score, and hospitalizations for stroke, hypertension, heart failure, peripheral vascular disease and circulatory diseases. **All treatment and demographic covariates were centered at their means. As a result, the coefficients on the year covariates in Models 1 (and 2) can be interpreted as the change in outcome for an average person (in an average area).

$\# \mathrm{p} \leq 0.05$

$\dagger \mathrm{p} \leq 0.01$ 
Figure 5. All CVD: Change in the probability of being disabled, dead, and non-disabled, $1994-1984$, by $10^{\text {th }}$ and $90^{\text {th }}$ percentiles of relevant procedure use

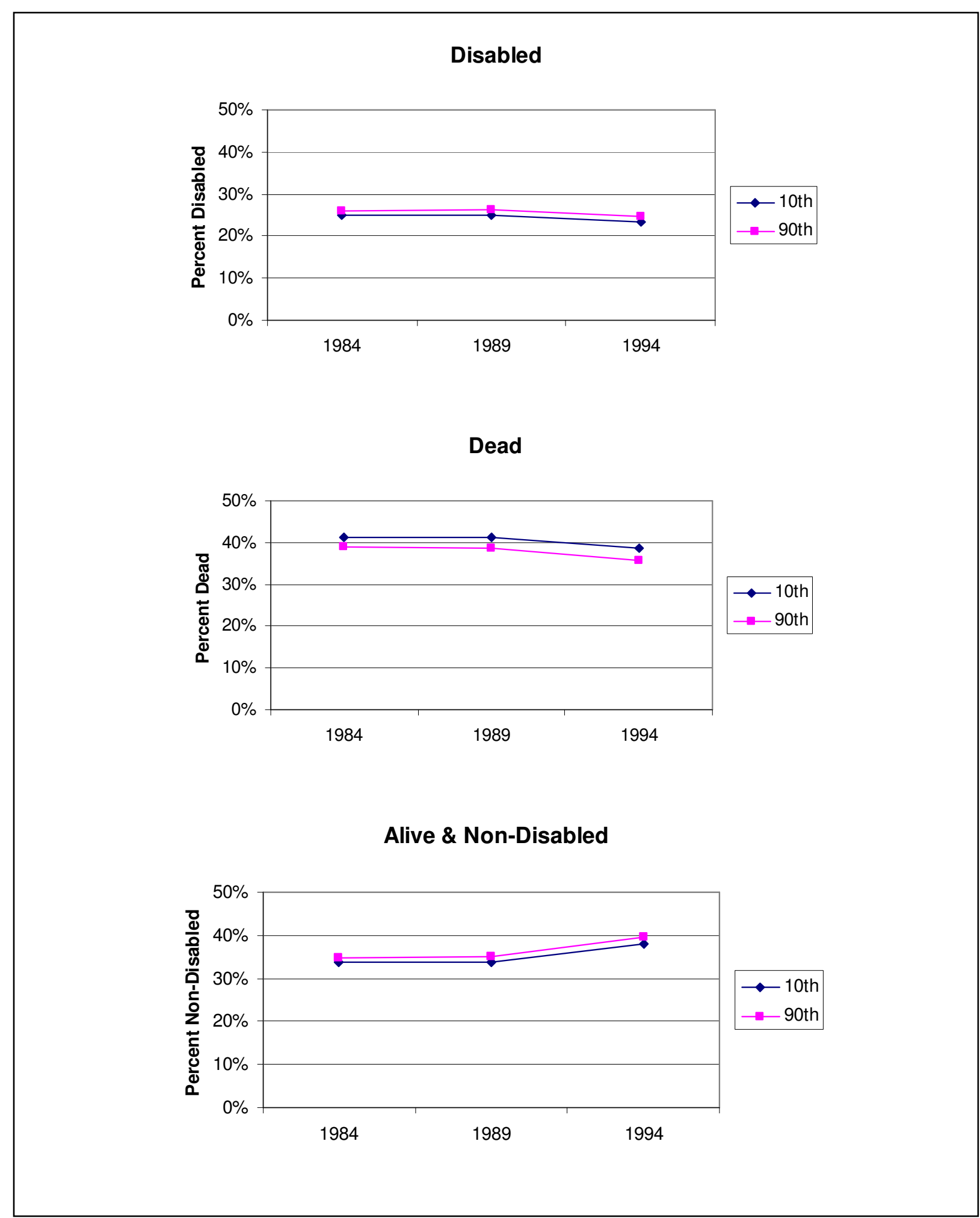


Figure 6. All CVD: Change in the probability of being disabled, dead, and non-disabled, $1994-1984$, by $10^{\text {th }}$ and $90^{\text {th }}$ percentiles of reperfusion, beta blocker, aspirin and aceinhibitor use

Disabled

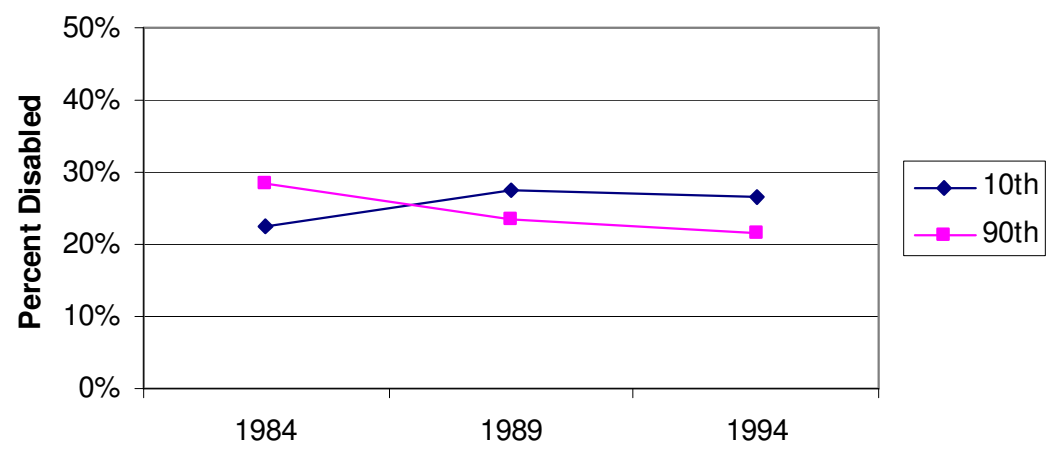

Dead

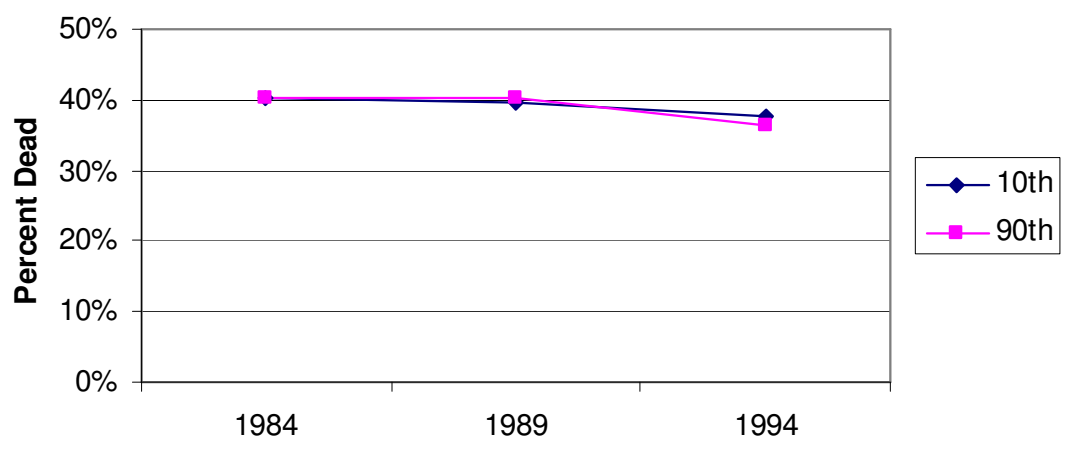

Alive \& Non-Disabled

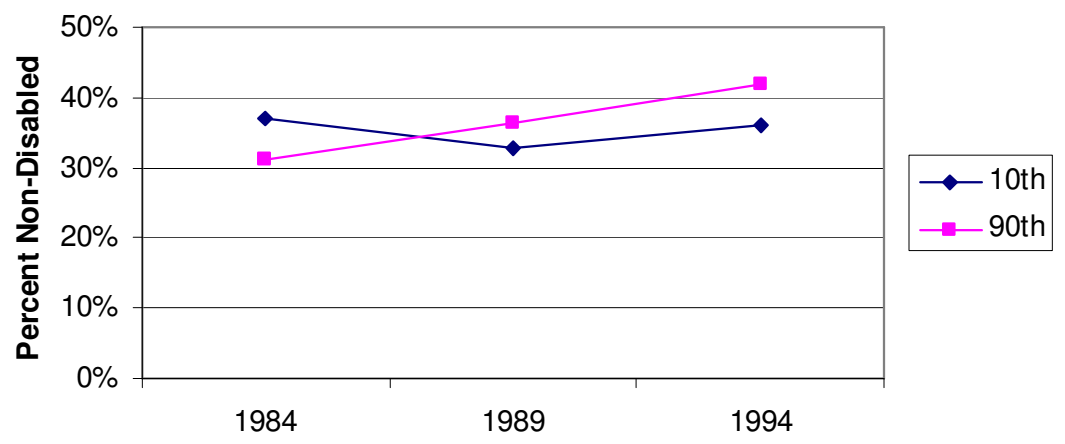


Table 7. Stroke: Multinomial Regression Models for Health Status Outcome 5 Years after Baseline Survey***

\begin{tabular}{|c|c|c|c|c|}
\hline & \multicolumn{2}{|c|}{ Model 1: } & \multicolumn{2}{|c|}{ Model 2: } \\
\hline Coefficients (SEs) & Disability & Death & Disability & Death \\
\hline Year89 & $0.05(0.18)$ & $-0.04(0.16)$ & $0.11(0.19)$ & $-0.01(0.17)$ \\
\hline Year94 & $-0.38(0.15) \#$ & $-0.44(0.14) \dagger$ & $-0.22(0.17)$ & $-0.34(0.17) \#$ \\
\hline Reperfusion & - & - & $0.02(0.01)$ & $0.01(0.01)$ \\
\hline Reperfusion*Year89 & - & - & $-0.02(0.02)$ & $-0.02(0.02)$ \\
\hline Reperfusion*Year94 & - & - & $-0.05(0.02) \dagger$ & $-0.02(0.02)$ \\
\hline Beta Blockers & - & - & $0.01(0.01)$ & $0.01(0.01)$ \\
\hline Beta Blockers*Year89 & - & - & $-0.02(0.02)$ & $-0.02(0.02)$ \\
\hline Beta Blockers*Year94 & - & - & $-0.02(0.01)$ & $-0.03(0.01) \#$ \\
\hline Aspirin & - & - & $-0.02(0.02)$ & $-0.00(0.02)$ \\
\hline Aspirin*Year89 & - & - & $-0.02(0.03)$ & $-0.06(0.03) \#$ \\
\hline Aspirin*Year94 & - & - & $0.04(0.04)$ & $0.01(0.03)$ \\
\hline Ace-Inhibitors & - & - & $0.01(0.01)$ & $0.01(0.01)$ \\
\hline Ace-Inhibitors*Year89 & - & - & $0.00(0.02)$ & $0.00(0.02)$ \\
\hline Ace-Inhibitors*Year94 & - & - & $-0.00(0.02)$ & $0.01(0.02)$ \\
\hline Warfarin & - & - & $-0.04(0.02)$ & $-0.02(0.02)$ \\
\hline Warfarin*Year89 & - & - & $0.02(0.04)$ & $0.03(0.04)$ \\
\hline Warfarin*Year94 & - & - & $0.02(0.03)$ & $0.01(0.04)$ \\
\hline Antithrombolytics & - & - & $0.03(0.04)$ & $-0.01(0.04)$ \\
\hline Antithrombolytics*Year89 & - & - & $-0.02(0.05)$ & $0.03(0.05)$ \\
\hline Antithrombolytics*Year94 & - & - & $-0.03(0.04)$ & $-0.03(0.05)$ \\
\hline Relevant procedures & - & - & $-0.01(0.01) \dagger$ & $0.00(0.01)$ \\
\hline \multicolumn{5}{|l|}{ F-tests } \\
\hline $\begin{array}{l}\text { For disability and death: } \\
\text { All HRR and state } \\
\text { variables }\end{array}$ & \multicolumn{2}{|c|}{ - } & 0.1750 & 0.0008 \\
\hline $\begin{array}{l}\text { Overall: All HRR and } \\
\text { state variables }\end{array}$ & \multicolumn{2}{|c|}{ - } & \multicolumn{2}{|c|}{0.0003} \\
\hline \multicolumn{5}{|l|}{ Model Statistics } \\
\hline $\mathrm{N}$ & \multicolumn{2}{|c|}{3355} & \multicolumn{2}{|c|}{3355} \\
\hline F-test & \multirow{2}{*}{\multicolumn{2}{|c|}{$\begin{array}{c}10.06 \\
<0001\end{array}$}} & \multicolumn{2}{|c|}{9.04} \\
\hline P-value & & & \multicolumn{2}{|c|}{$<0.0001$} \\
\hline
\end{tabular}

*Models also adjust for age and sex interactions, marital status, race (white vs. other), Charlson co-morbidity score, and hospitalizations for stroke, hypertension, heart failure, peripheral vascular disease and circulatory diseases.

**All treatment and demographic covariates were centered at their means. As a result, the coefficients on the year covariates in Models 1 (and 2) can be interpreted as the change in outcome for an average person (in an average area). $\# \mathrm{p} \leq 0.05$ $\dagger \mathrm{p} \leq 0.01$ 
Figure 8. Stroke: Change in the probability of being disabled, dead, and non-disabled, 1994 -1984, by $10^{\text {th }}$ and $90^{\text {th }}$ percentiles of relevant procedure use

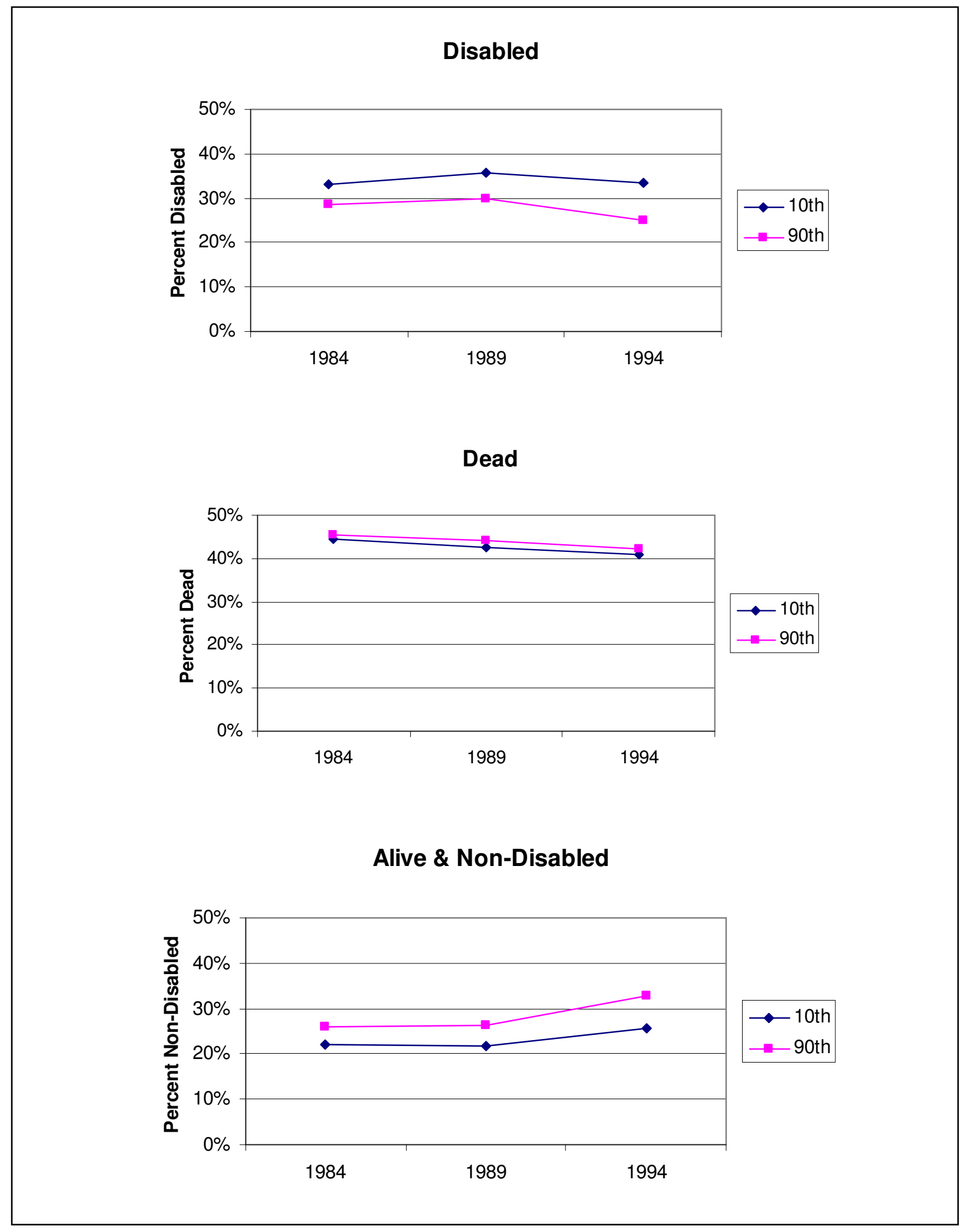


Figure 9. Stroke: Change in the probability of being disabled, dead, and non-disabled, 1994 -1984, by $10^{\text {th }}$ and $90^{\text {th }}$ percentiles of reperfusion, beta blocker, aspirin and ace-inhibitor use

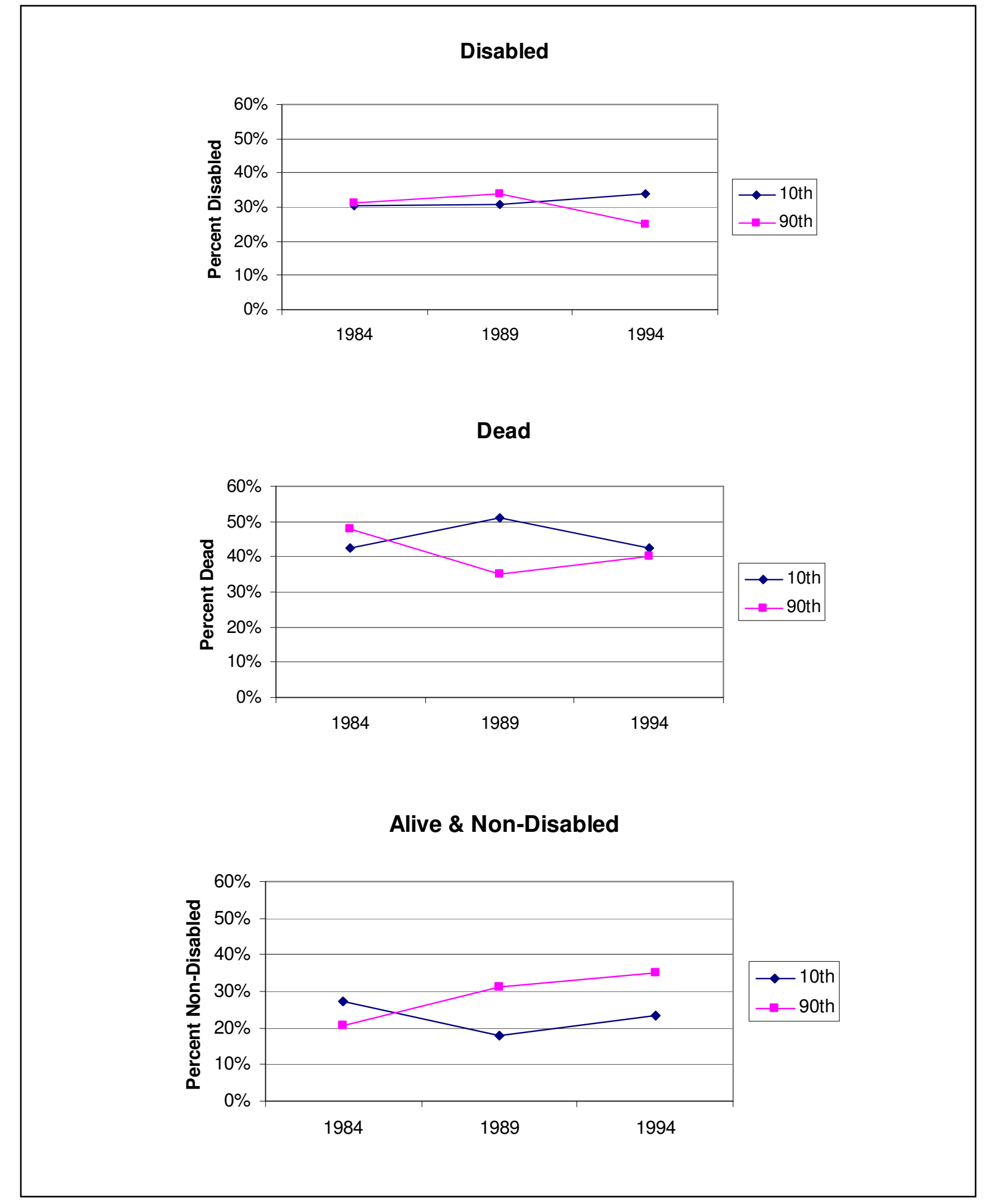


Table 8. Heart Failure \& Arrhythmia: Multinomial Regression Models for Health Status Outcome 5 Years after Baseline Survey* **

\begin{tabular}{|c|c|c|c|c|}
\hline & \multicolumn{2}{|c|}{ Model 1: } & \multicolumn{2}{|c|}{ Model 2: } \\
\hline Coefficients (SEs) & Disability & Death & Disability & Death \\
\hline Year89 & $0.07(0.16)$ & $-0.10(0.13)$ & $0.04(0.16)$ & $-0.12(0.13)$ \\
\hline Year94 & $-0.23(0.17)$ & $-0.39(0.16) \#$ & $-0.25(0.17)$ & $-0.41(0.14) \dagger$ \\
\hline Reperfusion & - & - & $-0.01(0.01)$ & $-0.02(0.01)$ \\
\hline Reperfusion*Year89 & - & - & $0.01(0.02)$ & $0.02(0.02)$ \\
\hline Reperfusion*Year94 & - & - & $0.01(0.02)$ & 0.04 (0.02)\# \\
\hline Beta Blockers & - & - & $-0.01(0.01)$ & $0.01(0.01)$ \\
\hline Beta Blockers*Year89 & - & - & $0.01(0.02)$ & $-0.00(0.01)$ \\
\hline Beta Blockers*Year94 & - & - & $-0.02(0.02)$ & $-0.02(0.01)$ \\
\hline Aspirin & - & - & $0.01(0.02)$ & $-0.01(0.01)$ \\
\hline Aspirin*Year89 & - & - & $-0.02(0.03)$ & $-0.00(0.03)$ \\
\hline Aspirin*Year94 & - & - & $-0.01(0.03)$ & $0.00(0.02)$ \\
\hline Ace-Inhibitors & - & - & $0.01(0.01)$ & $-0.01(0.01)$ \\
\hline Ace-Inhibitors*Year89 & - & - & $0.01(0.02)$ & $0.01(0.02)$ \\
\hline Ace-Inhibitors*Year89 & - & - & $0.02(0.02)$ & $0.03(0.02)$ \\
\hline $\begin{array}{l}\text { Evaluation of Ejection } \\
\text { Fraction }\end{array}$ & - & - & $-0.03(0.02)$ & $-0.04(0.02) \#$ \\
\hline $\begin{array}{l}\text { Eval. Ejec; Frac.* } \\
\text { Year89 }\end{array}$ & - & - & $-0.01(0.03)$ & $0.04(0.03)$ \\
\hline $\begin{array}{l}\text { Eval. Ejec; Frac.* } \\
\text { Year94 }\end{array}$ & - & - & $0.01(0.03)$ & $0.00(0.03)$ \\
\hline Relevant procedures & - & - & $-0.00(0.01)$ & $0.00(0.01)$ \\
\hline \multicolumn{5}{|l|}{ F-tests } \\
\hline $\begin{array}{l}\text { For disability and } \\
\text { death: All HRR and } \\
\text { state variables }\end{array}$ & & 0.0434 & 0.0869 \\
\hline $\begin{array}{l}\text { Overall: All HRR and } \\
\text { state variables }\end{array}$ & & \multicolumn{2}{|c|}{0.0071} \\
\hline \multicolumn{5}{|l|}{ Model Statistics } \\
\hline $\mathrm{N}$ & \multicolumn{2}{|c|}{3752} & \multicolumn{2}{|c|}{3752} \\
\hline F-test & \multirow{2}{*}{\multicolumn{2}{|c|}{$\frac{17.12}{<00001}$}} & \multirow{2}{*}{\multicolumn{2}{|c|}{$\frac{12.29}{<00001}$}} \\
\hline P-value & & & & \\
\hline
\end{tabular}

*Models also adjust for age and sex interactions, marital status, race (white vs. other), Charlson co-morbidity score, and hospitalizations for stroke, hypertension, ischemic heart disease, peripheral vascular disease and circulatory diseases.

**All treatment and demographic covariates were centered at their means. As a result, the coefficients on the year covariates in Models 1 (and 2) can be interpreted as the change in outcome for an average person (in an average area).

$\# \mathrm{p} \leq 0.05$

$\dagger p \leq 0.01$ 
Figure 9. Heart Failure \& Arrhythmia: Change in the probability of being disabled, dead, and non-disabled, $1994-1984$, by $10^{\text {th }}$ and $90^{\text {th }}$ percentiles of relevant procedure use

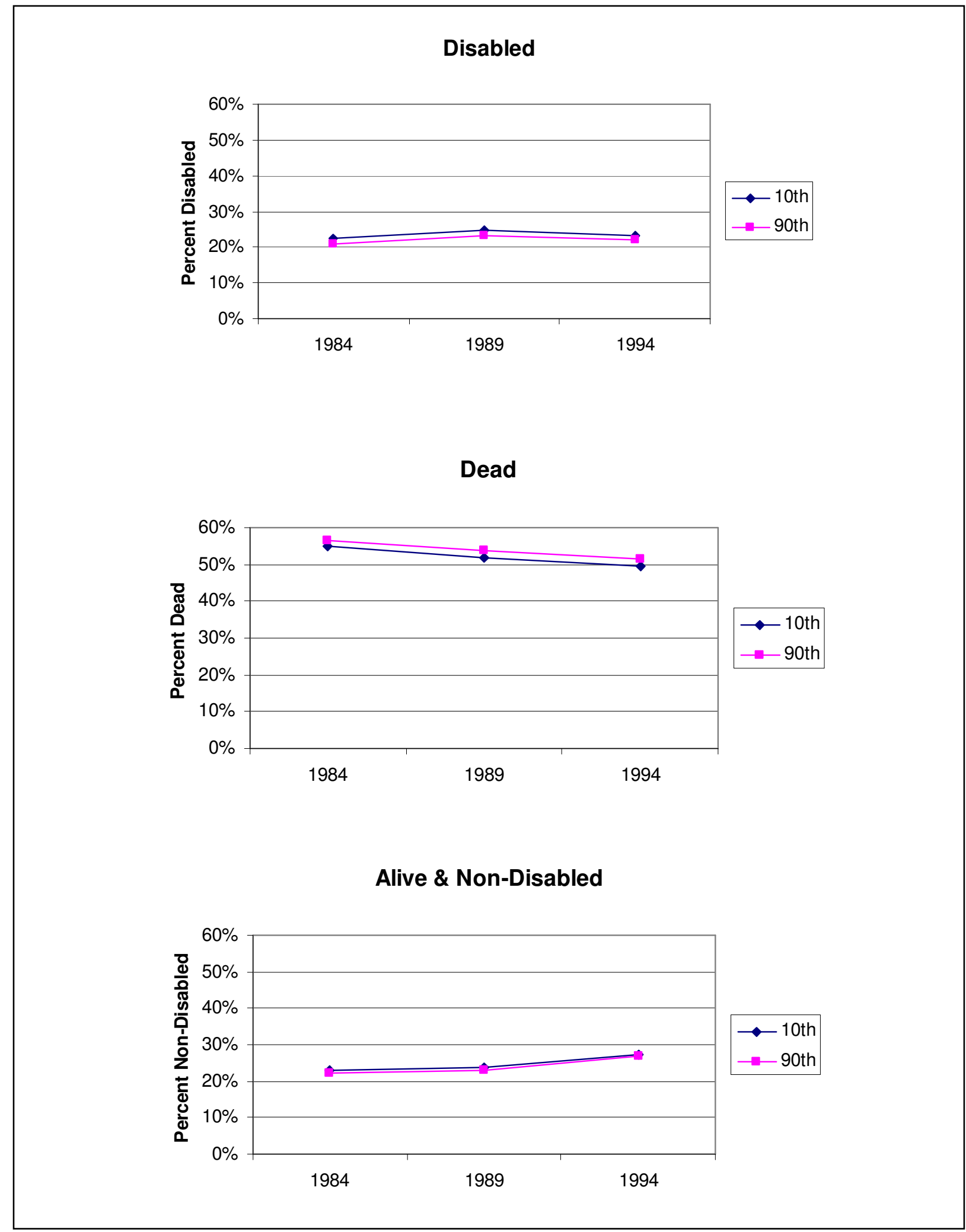


Figure 10. Heart Failure \& Arrhythmia: Change in the probability of being disabled, dead, and non-disabled, 1994-1984, by $10^{\text {th }}$ and $90^{\text {th }}$ percentiles of reperfusion, beta blocker, aspirin and ace-inhibitor use

\section{Disabled}

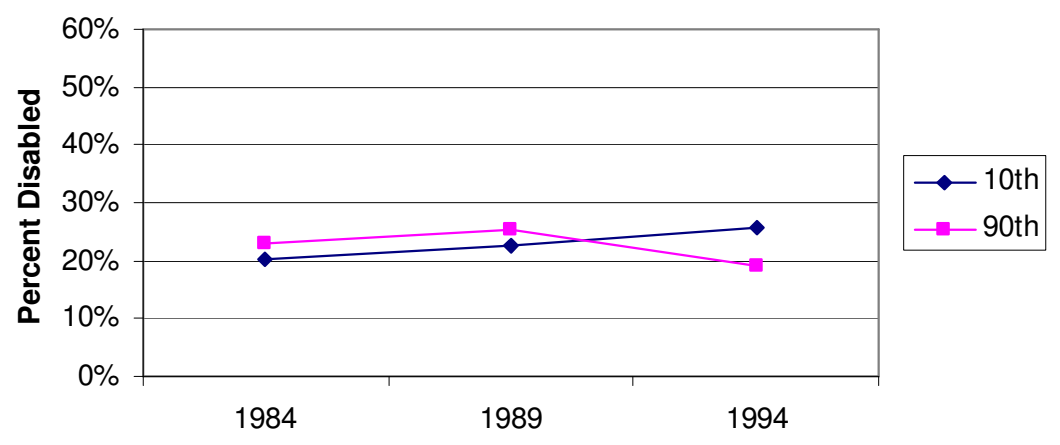

Dead

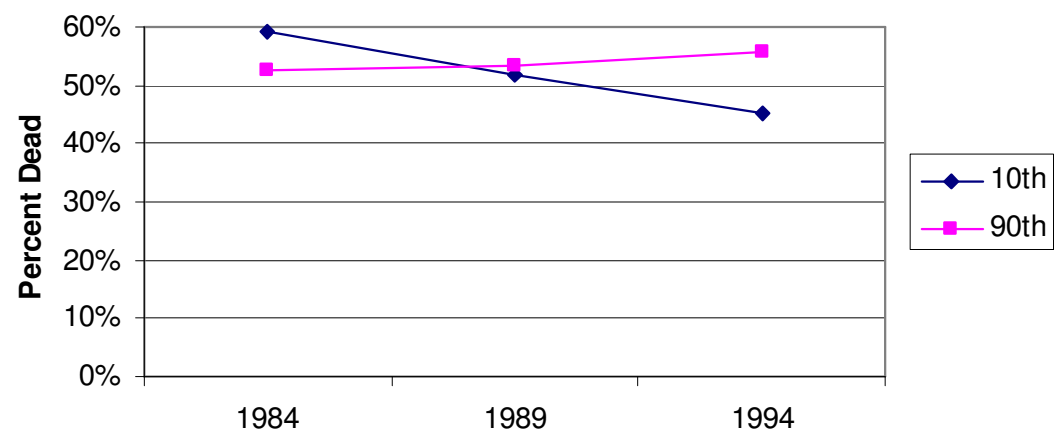

Alive \& Non-Disabled

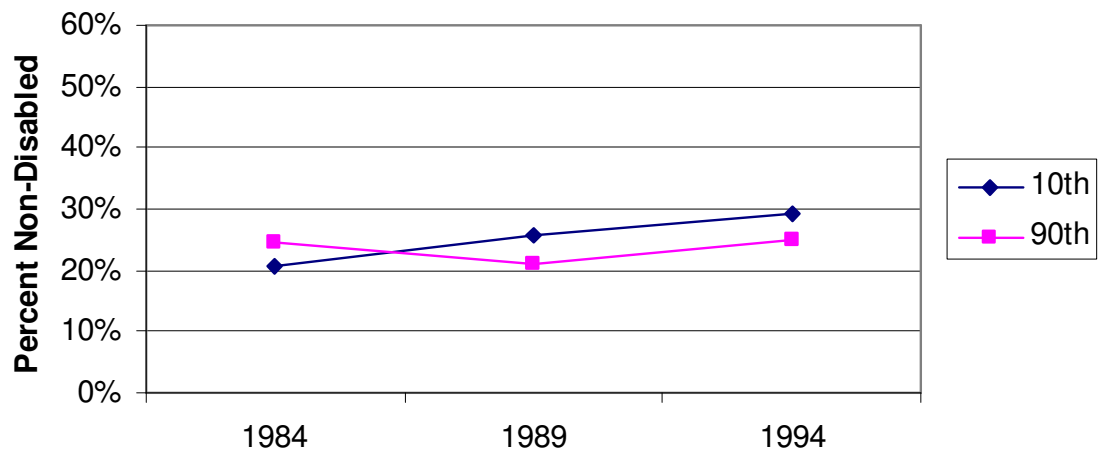


Table 9. Circulatory Diseases: Multinomial Regression Models for Health Status Outcome 5 Years after Baseline Survey* **

\begin{tabular}{|c|c|c|c|c|}
\hline & \multicolumn{2}{|c|}{ Model 1: } & \multicolumn{2}{|c|}{ Model 2: } \\
\hline Coefficients (SES) & Disability & Death & Disability & Death \\
\hline Year89 & $0.11(0.15)$ & $0.13(0.15)$ & $0.10(0.15)$ & $0.13(0.15)$ \\
\hline Year94 & $-0.37(0.15) \#$ & $-0.34(0.16) \#$ & $-0.38(0.16) \#$ & $-0.28(0.15)$ \\
\hline Reperfusion & - & - & $0.02(0.01)$ & $0.01(0.01)$ \\
\hline Reperfusion*Year89 & - & - & $-0.03(0.02)$ & $0.00(0.02)$ \\
\hline Reperfusion*Year94 & - & - & $-0.05(0.02) \#$ & $-0.02(0.02)$ \\
\hline Beta Blockers & - & - & $-0.01(0.01)$ & $0.01(0.01)$ \\
\hline Beta Blockers*Year89 & - & - & $-0.02(0.01)$ & $-0.02(0.01)$ \\
\hline Beta Blockers*Year94 & - & - & $-0.02(0.01)$ & $-0.04(0.01) \dagger$ \\
\hline Aspirin & - & - & $0.00(0.02)$ & $-0.01(0.02)$ \\
\hline Aspirin*Year89 & - & - & $0.01(0.02)$ & $0.01(0.03)$ \\
\hline Aspirin*Year94 & - & - & $-0.00(0.03)$ & $0.02(0.03)$ \\
\hline Ace-Inhibitors & - & - & $0.01(0.01)$ & $0.00(0.01)$ \\
\hline Ace-Inhibitors*Year89 & - & - & $-0.01(0.02)$ & $0.01(0.02)$ \\
\hline Ace-Inhibitors*Year94 & - & - & $-0.01(0.02)$ & $0.00(0.02)$ \\
\hline Relevant procedures & - & - & $0.00(0.00)$ & $-0.00(0.00)$ \\
\hline \multicolumn{5}{|l|}{ F-tests } \\
\hline $\begin{array}{l}\text { For disability and } \\
\text { death: All HRR } \\
\text { variables }\end{array}$ & \multicolumn{2}{|c|}{ - } & 0.0435 & 0.1461 \\
\hline \multirow[t]{2}{*}{$\begin{array}{l}\text { Overall: All HRR } \\
\text { variables }\end{array}$} & \multicolumn{2}{|c|}{ - } & \multicolumn{2}{|c|}{0.0246} \\
\hline & \multicolumn{2}{|c|}{ - } & & \\
\hline \multicolumn{5}{|l|}{ Model Statistics } \\
\hline $\mathrm{N}$ & \multicolumn{2}{|c|}{2969} & \multicolumn{2}{|c|}{2969} \\
\hline F-test & \multirow{2}{*}{\multicolumn{2}{|c|}{$\frac{12.63}{<0.0000}$}} & \multicolumn{2}{|c|}{8.93} \\
\hline P-value & & & \multicolumn{2}{|c|}{$<0.0001$} \\
\hline
\end{tabular}

*Models also adjust for age and sex interactions, marital status, race (white vs. other), Charlson co-morbidity score, and hospitalizations for stroke, hypertension, heart failure, peripheral vascular disease and circulatory diseases.

**All treatment and demographic covariates were centered at their means. As a result, the coefficients on the year covariates in Models 1 (and 2) can be interpreted as the change in outcome for an average person (in an average area).

$\# \mathrm{p} \leq 0.05$

$\dagger \mathrm{p} \leq 0.01$ 
Figure 11. Other Circulatory Diseases: Change in the probability of being disabled, dead, and non-disabled, $1994-1984$, by $10^{\text {th }}$ and $90^{\text {th }}$ percentiles of relevant procedure use

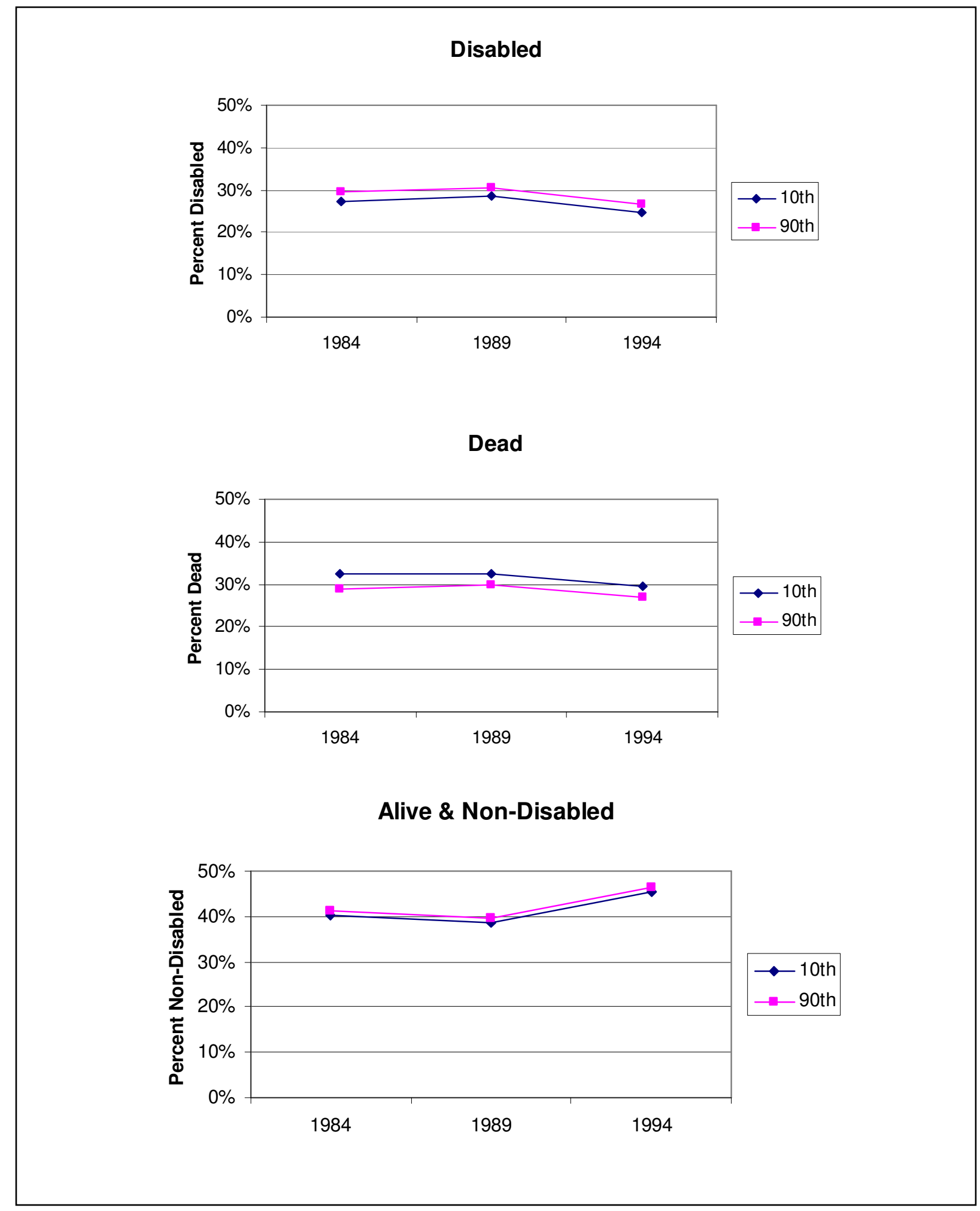


Figure 12. Other Circulatory Diseases: Change in the probability of being disabled, dead, and non-disabled, $1994-1984$, by $10^{\text {th }}$ and $90^{\text {th }}$ percentiles of reperfusion, beta blocker, aspirin and ace-inhibitor use

\section{Disabled}

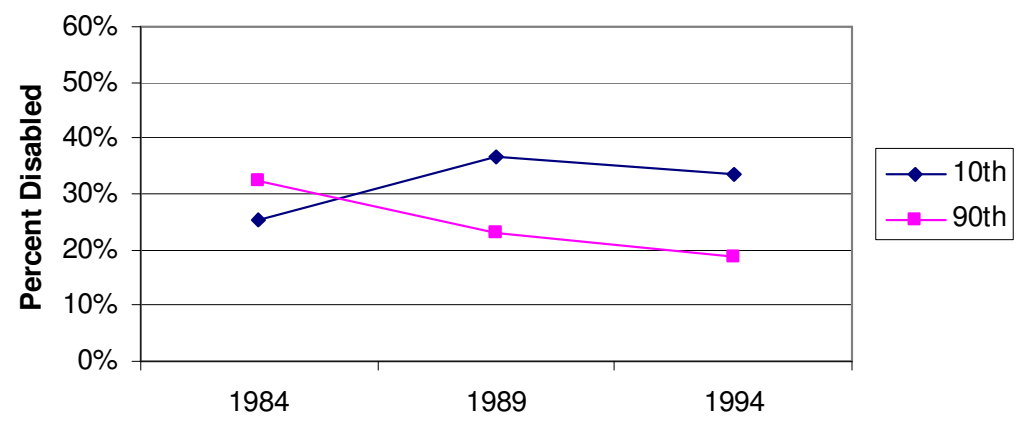

Dead

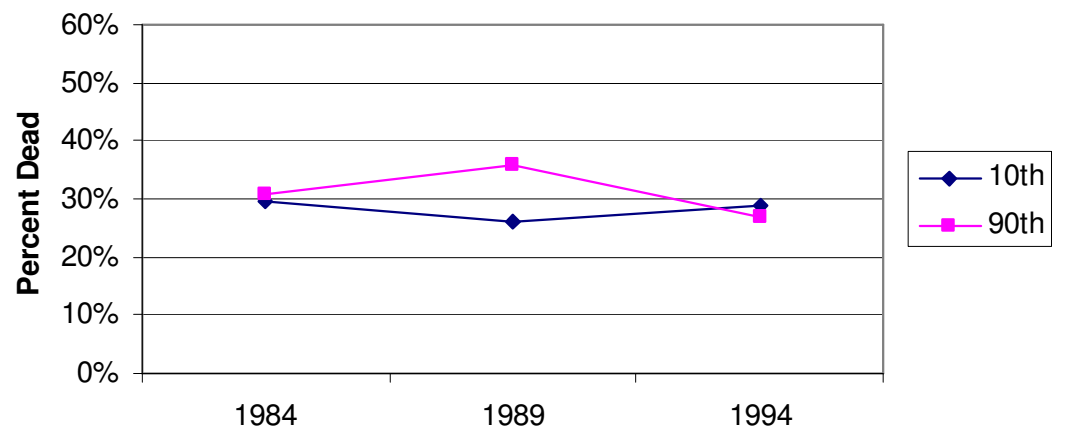

Alive \& Non-Disabled

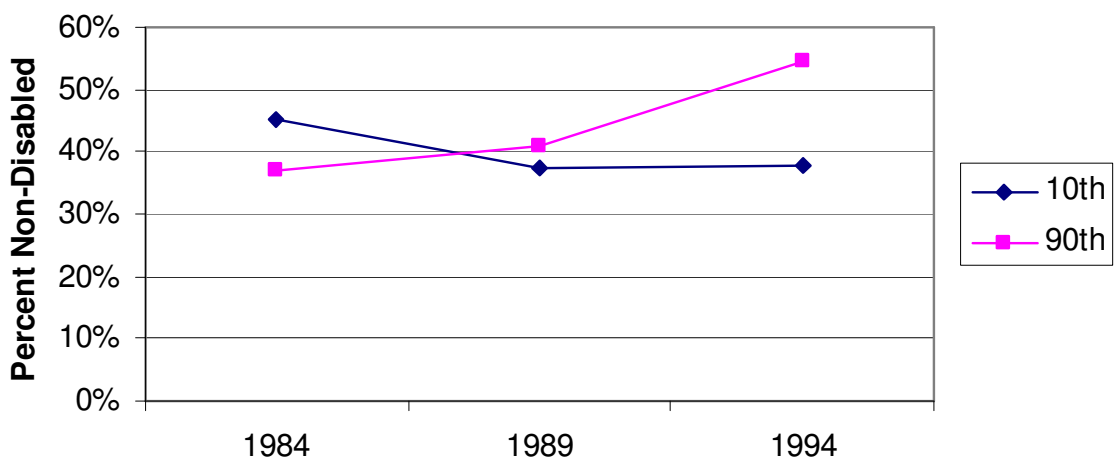


Figure 13. Survival by disability and year

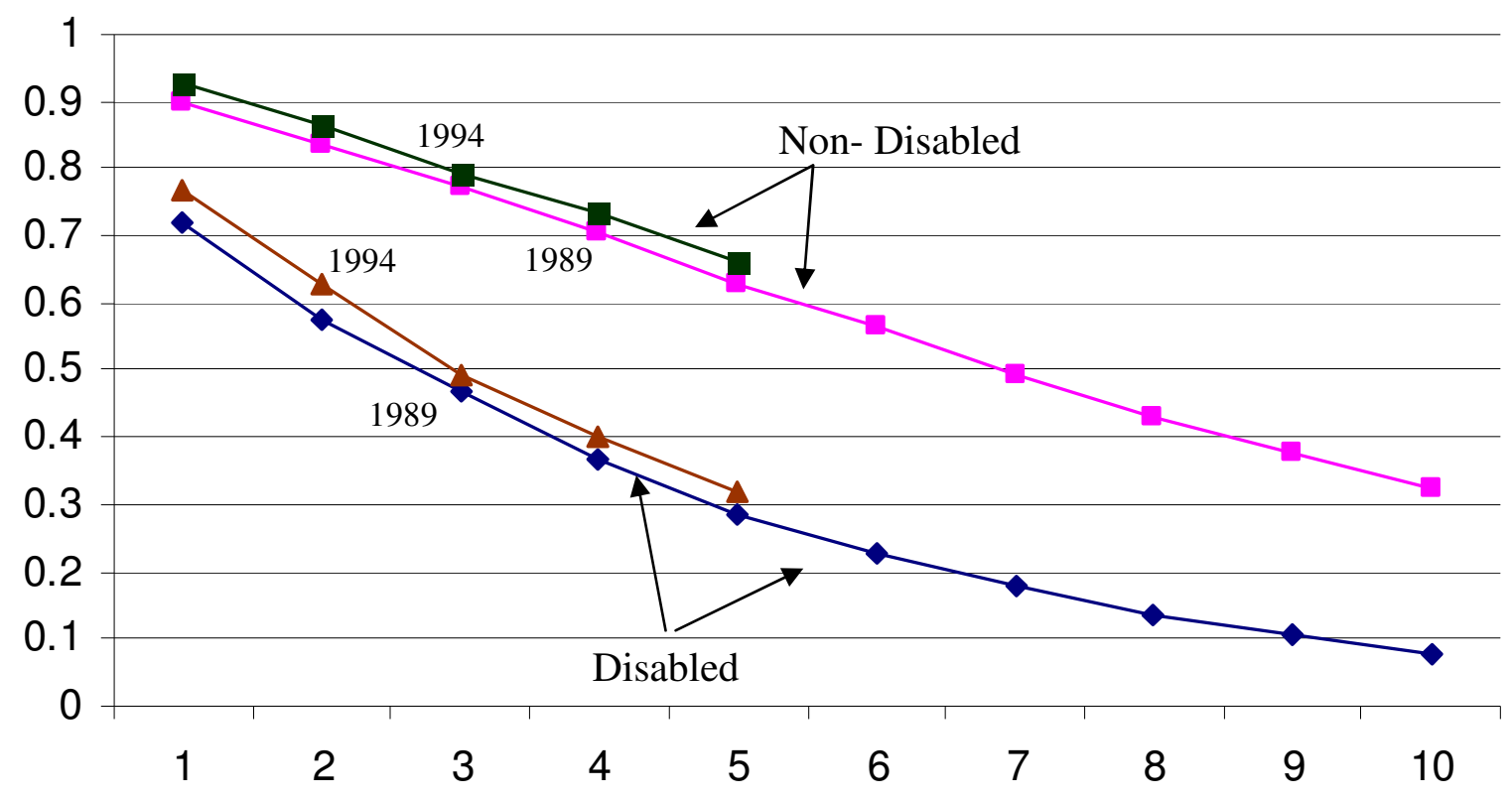




\begin{tabular}{|l|c|c|}
\hline \multicolumn{3}{|c|}{ Table 10: The Persistence of Disability Status Across Surveys } \\
\hline Cohort & $\begin{array}{c}\text { Not Disabled } \\
\text { at Baseline }\end{array}$ & Disabled at Baseline \\
\hline 1989 Cohort & & 79.1 \\
\hline Pr[Disabled in 1994] & 31.4 & 72.1 \\
\hline Pr[Disabled in 1999] & 36.9 & \\
\hline \multicolumn{2}{|c|}{} & 83.9 \\
\hline 1994 Cohort & & \\
\hline Pr[Disabled in 1999] & 25.2 & \\
\hline Note: Disability frequencies are conditional on being alive at follow-up \\
\hline
\end{tabular}




\begin{tabular}{|l|c|c|c|}
\hline Table 11: Life Expectancy by Disability Status \\
\hline Measure & $\begin{array}{c}\text { Not } \\
\text { Disabled }\end{array}$ & Disabled & Difference \\
\hline Life expectancy & 7.8 & 5.1 & 2.7 \\
\hline $\begin{array}{l}\text { Quality adjusted life } \\
\text { expectancy }\end{array}$ & 6.7 & 3.0 & 3.7 \\
\hline Source: Details about the calculations are described in text. \\
\hline
\end{tabular}

